\title{
Role of Copper on Mitochondrial Function and Metabolism
}

\author{
Lina M. Ruiz ${ }^{1}$, Allan Libedinsky ${ }^{2,3}$ and Alvaro A. Elorza ${ }^{2,3 *}$ \\ ${ }^{1}$ Institute of Biomedical Sciences, Faculty of Health Sciences, Universidad Autónoma de Chile, Santiago, Chile, ${ }^{2}$ Institute of \\ Biomedical Sciences, Faculty of Medicine and Faculty of Life Sciences, Universidad Andres Bello, Santiago, Chile, ${ }^{3}$ Millennium \\ Institute on Immunology and Immunotherapy, Santiago, Chile
}

\section{OPEN ACCESS}

Edited by:

Qingping Dou,

Wayne State University, United States

Reviewed by:

Xin Chen,

Guangzhou Medical University, China

Chiara Nardon,

University of Verona, Italy

*Correspondence:

Alvaro A. Elorza

alvaro.elorza@unab.cl

Specialty section:

This article was submitted to

Cellular Biochemistry,

a section of the journal

Frontiers in Molecular Biosciences

Received: 18 May 2021

Accepted: 05 July 2021

Published: 24 August 2021

Citation:

Ruiz LM, Libedinsky A and Elorza AA

(2021) Role of Copper on

Mitochondrial Function and Metabolism.

Front. Mol. Biosci. 8:711227. doi: 10.3389/fmolb.2021.711227
Copper is essential for life processes like energy metabolism, reactive oxygen species detoxification, iron uptake, and signaling in eukaryotic organisms. Mitochondria gather copper for the assembly of cuproenzymes such as the respiratory complex IV, cytochrome c oxidase, and the antioxidant enzyme superoxide dismutase 1. In this regard, copper plays a role in mitochondrial function and signaling involving bioenergetics, dynamics, and mitophagy, which affect cell fate by means of metabolic reprogramming. In mammals, copper homeostasis is tightly regulated by the liver. However, cellular copper levels are tissue specific. Copper imbalances, either overload or deficiency, have been associated with many diseases, including anemia, neutropenia, and thrombocytopenia, as well as tumor development and cancer aggressivity. Consistently, new pharmacological developments have been addressed to reduce or exacerbate copper levels as potential cancer therapies. This review goes over the copper source, distribution, cellular uptake, and its role in mitochondrial function, metabolic reprograming, and cancer biology, linking copper metabolism with the field of regenerative medicine and cancer.

Keywords: mitochondria, copper, metabolic reprograming, hematopoietic stem cells (HSCs), cancer, ROS, proliferation, differentiation

\section{INTRODUCTION}

Mitochondria behave as biological microchips and constitute an integrated metabolic circuit that receives, processes, and transmits various signals to manage cell fate, that is, cellular proliferation, differentiation, and death. Beyond ATP and heat generation, mitochondria are directly involved in the epigenetics and transcriptional control of gene expression to rewire cell metabolism to new environmental conditions (Anderson et al., 2019; Hu et al., 2020).

The power of mitochondria and their ability to control cell metabolism and fate are based on the generation of the proton motive force (PMF) by the electron transport chain (ETC), which localizes in the inner mitochondrial membrane (IMM). The ETC is composed of the respiratory complex I (CI) NADH dehydrogenase, complex II (CII) succinate dehydrogenase, complex III (CIII) ubiquinol

\footnotetext{
Abbreviations: ATOX1, antioxidant 1 copper chaperone; CDM, copper-depleting moiety; CDN, copper-depleting nanoparticle; COX, cytochrome C oxidase, complex IV; CTR1, copper transport protein; CuL, low molecular weight copper ligand; D-Pen, D-penicillamine; ETC, electron transport chain; HCC, human hepatocellular carcinoma; HSCs, hematopoietic stem cells; IMS, mitochondrial intermembrane space; MYC, MYC proto-oncogene; BHLH transcription factor; OXPHOS, oxidative phosphorylation system; PMF, proton motive force; SOD1, copper/zinc superoxide dismutase; SOD2, Mn-superoxide dismutase; SPN, semiconducting polymer nanoparticle; TEPA, tetraethylenepentamine; TM, tetrathiomolybdate.
} 
cytochrome c reductase, complex IV (CIV) cytochrome c oxidase, and the mobile electron carriers: coenzyme Q and cytochrome $\mathrm{c}$. The ETC can be found in different configurations or arrays, varying from individual complexes to supramolecular associations, called supercomplexes or respirasomes, that are typically built of a monomer of CI, a dimer of CIII, and up to four monomers of CIV (I1III2IV0-4) (Schagger and Pfeiffer 2000; Boekema and Braun 2007; Huttemann et al., 2007; Acin-Perez et al., 2008; Dudkina et al., 2008). Unknown factors regulate the ratio between individual and assembled complexes, but it is likely to be dependent on cell physiology and energetic needs (Dudkina et al., 2008).

The proper assembly and functioning of the ETC is copper dependent (Kim et al., 2008; Turski and Thiele 2009). This transition metal is a prosthetic group of CIV and plays a direct role in the generation of the PMF. Furthermore, copper is a cofactor of the copper/zinc superoxide dismutase (SOD1), a protein located in both the cytosol and the mitochondrial inner membrane space to relieve the ETC-generated ROS (for the mitochondrial matrix ROS, there is an Mn-superoxide dismutase, SOD2) (McCord and Fridovich 1969; Yonashiro et al., 2009; Mondola et al., 2016). The indirect role of copper on mitochondrial function is related to the mitochondrial iron uptake since it is a cofactor of ferroxidases (Xu W. et al, 2013; Vallières et al., 2017). Iron transport is the key for iron-sulfur (FeS) cluster assembly and heme biosynthesis (Lill and Freibert 2020).

Hallmarks of dysfunctional copper metabolism are Wilson's and Menkes diseases which are inherited disorders. Patients with Wilson's disease accumulate copper in the liver due to the defective protein transporter, ATP7B. Copper overload produces liver cirrhosis, neurodegeneration, and anemia mostly via the exacerbation of hydroxyl radical production by the Fenton and Haber-Weiss reactions. Copper toxicity decreases mitochondrial respiration and induces apoptosis (Medeiros and Jennings 2002; Su et al., 2011; Jia et al., 2012). On the other hand, Menkes disease features mutations in the transporter ATP7A which affect the release of copper from the enterocyte to the bloodstream, causing a severe copper deficiency that in most of cases results in death due to CIV and SOD1 dysfunction (Rossi et al., 2004; Horn and Barrientos 2008; Kim et al., 2008; Turski and Thiele 2009). Common clinical manifestations of copper deficiency are anemia, bone marrow dysplasia, neutropenia, and neuromyelopathy (Gregg et al., 2002; Fong et al., 2007; Bolamperti et al., 2009; Jaiser and Winston 2010), and the appearance of enlarged mitochondria. These giant mitochondria or mega-mitochondria have been described in early precursors of the bone marrow, hepatocytes, and myocardium under copper deprivation, copper chelator treatments, and starvation in humans and rats (Dallman and Goodman 1970; Goodman et al., 1970; Gallagher et al., 1973; Wakabayashi 2002; Bustos et al., 2013; Ruiz et al., 2014). A mild copper deficiency in a murine model evoked mitochondrial adaptive responses involving the oxidative phosphorylation system (OXPHOS) remodeling and mitochondrial dynamic alterations, with upregulation of fusion proteins MFN-2 and OPA1 associated with a particular big mitochondrial morphology including normal and swollen mitochondria (Ruiz et al., 2014). Also, the generation of bigger mitochondria after copper deficiency in erythropoietic cells, cell line K562 and primary human $\mathrm{CD} 34^{+}$, was related to the induction of mitochondrial fusion through upregulation of MFN-2 and OPA1 (Bustos et al., 2013).

Although heavy copper deficiency and overload have been associated with exacerbated ROS production and cell death due to mitochondrial dysfunction, noncytotoxic variations of the cellular copper levels may influence cell proliferation or differentiation through the reprogramming of mitochondrial metabolism, which can manage the balance between glycolysis and oxidative phosphorylation as well as the production of ROS, making the cellular environment oxidative (Bustos et al., 2013; Ruiz et al., 2016; Jensen et al., 2019). This exciting topic links copper metabolism with the field of regenerative medicine and cancer. In this review, we analyzed the acquisition of copper by the organisms and cells and the role of copper on mitochondrial function involving bioenergetics, dynamics, and mitophagy, and how this affects cell fate through metabolic reprogramming.

\section{COPPER UPTAKE AND PHYSIOLOGY}

Copper is mainly obtained from solid foods (Supplementary Table S1, Supplementary Material) and drinking water (Council et al., 2000). The recommended intake of copper in humans should be less than $1.5 \mathrm{mg} / \mathrm{d}$ since $0.8 \mathrm{mg} / \mathrm{d}$ is enough to regulate and maintain copper status in the body. After the digestion of foods in the stomach and duodenum, copper is absorbed by cells of the intestinal mucosa, the enterocytes, which are also responsible for releasing copper into the blood plasma. When in excess, the ingested copper will be directly excreted through the feces, but when in lack, cellular mechanisms will be activated to allow greater intestinal uptake (Turnlund et al., 1998; Larin et al., 1999). The uptake efficiency of this metal is high, reaching $55-75 \%$ in adults (Johnson et al., 1992). Of note, copper concentration is tissue-dependent, varying between $3 \mathrm{mg}$ (kidneys) and $46 \mathrm{mg}$ (skeleton) (average adult $\approx 70 \mathrm{~kg}$ ) (Linder 1991). Thus, the use of copper is different for each cell, and the effects produced by the imbalances of this metal will be tissue-specific. SupplementaryTable S1 (Supplementary Material) shows the amount of copper found in different kinds of food.

There are two phases for copper distribution into the organism (Owen 1971). Phase one: from food to the liver and kidneys via albumin and transcuprein. Phase two: from liver to other tissues and organs, such as heart, lungs, brain, and others via ceruloplasmin. The excess of copper must return to the liver, where it is again processed and incorporated into the bile which is the primary pathway for copper elimination from the body. However, some other fluids may transport copper to the intestine for excretion, such as the gastric and duodenal fluid. SupplementaryTable S2 (Supplementary Material) shows the concentrations of copper present in human fluids. Bile has the highest level of copper after blood. Copper entering the digestive tract through bile and other fluids becomes almost five times 


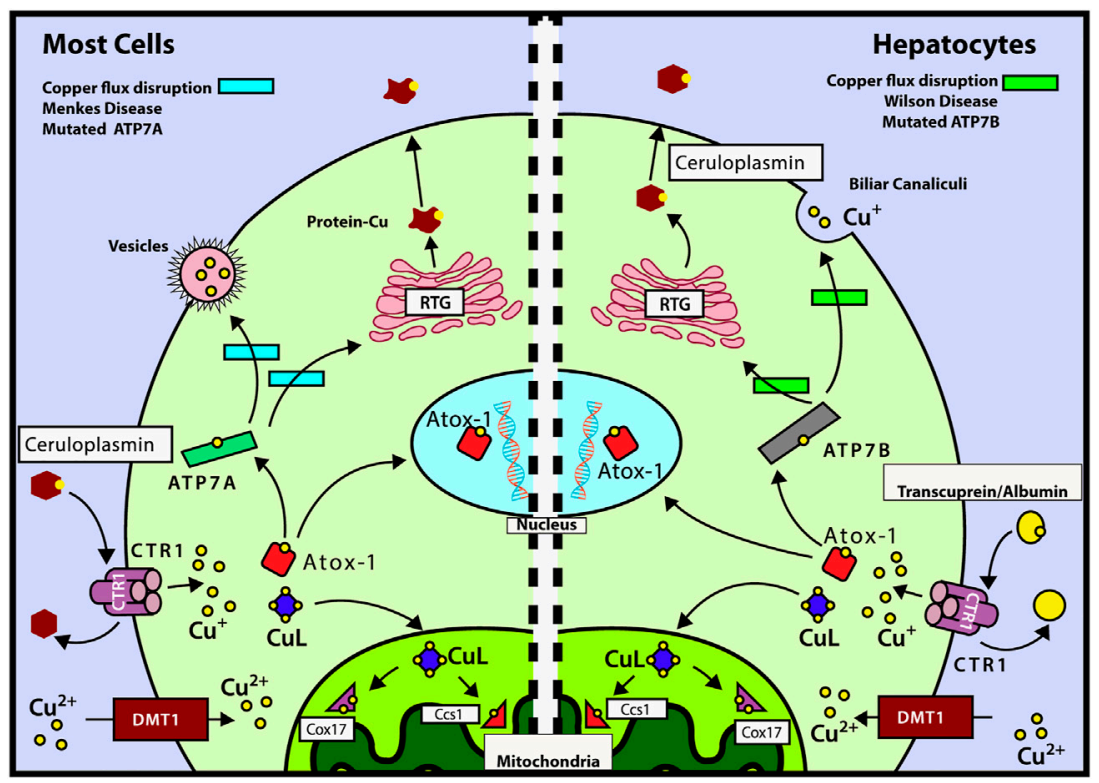

FIGURE 1 | Mechanisms of intracellular copper transport. After $\mathrm{Cu}$ is delivered to CTR1 by transcuprein/albumin/ceruloplasmin, it is translocated to cytosol, where it can be transferred either to mitochondria by copper ligand CuL or incorporated into ATOX1. ATOX1 can translocate into nucleus, by a copper-mediated mechanism, and deliver its copper to ATP7A/B. Left panel: mechanisms of copper transport for most cells (except hepatocytes). ATOX1 delivers Cu to ATP7A which in turn transports it to the TGN or transfers it into vesicles to be excreted out of the cell. During copper deficiency and excess, metallothioneins MT-I and MT-II regulate ATP7A trafficking and control cell viability (Gudekar et al., 2020). Right panel: mechanisms of copper transport for hepatocytes. ATOX1 donates copper to ATP7B which transports it to the trans-Golgi network (TGN) for incorporation into ceruloplasmin. ATP7B is also responsible for the transport of Cu to the cellular periphery to be incorporated into the bile (main incharge of copper excretion). Also, we can observe the routes affected by the diseases of Wilson and Menkes in the green and light blue rectangles, respectively. Modified from the study by Fischer and Goode (1994), Puig and Thiele (2002), Cobine et al. (2006a), Cobine et al. (2006b), and Qin et al. (2008).

greater than copper consumed in the diet. However, only about $0.5-1.0 \mathrm{mg} \mathrm{Cu}$ is excreted. Most of it, about $4.5-5.5 \mathrm{mg} \mathrm{Cu}$, is reabsorbed to maintain homeostasis of this metal (Linder and Roboz 1986).

Copper is transported inside the cell by the CTR1 (copper transport protein) transporter and then delivered to ATOX1 (antioxidant 1 copper chaperone) and $\mathrm{CuL}$ (low molecular weight copper ligand). The latter transports copper into mitochondria, specifically to COX17 (copper chaperone of cytochrome $\mathrm{C}$ oxidase [COX]) and CCS1 (copper chaperone of SOD1) (Puig and Thiele 2002). Figure 1 shows the mechanisms of intracellular copper transport in human cells.

\section{GETTING COPPER INTO MITOCHONDRIA}

Mitochondria need copper mainly for complex IV (COX) and SOD1 among other proteins (Table 1). CIV has two copper ions and is involved in the generation of the PMF and the complete reduction of oxygen to water in the ETC; SOD1 has one copper ion and is an antioxidant enzyme dealing with anion superoxide. In eukaryotes, mitochondrial copper is stored in the cytosolic anionic ligand $(\mathrm{CuL})$ complex, and its release requires high regulation for the efficient metalation of COX and SOD1. This highly regulated mechanism is probably due to the limited availability of this ion in the cytosol and the need for an immediate source of copper for the assembly of COX (Leary et al., 2009b).

Copper delivery into mitochondria is performed by the $\mathrm{CuL}$, which is a non-proteinaceous low molecular weight complex found in the cytosol and the mitochondrial matrix (Leary et al., 2009b; Vest et al., 2013). The biochemical properties of the CuL are conserved from yeasts to humans (Cobine et al., 2004), debating that its functional significance started early in evolution (Leary et al., 2009b). It is currently thought that the binding of copper (copper-free) to the $\mathrm{CuL}$ in the cytosol triggers its translocation to the mitochondrial intermembrane space (IMS) by means of the solute carrier family 25 member 3 (SLC25A3), the mammalian homolog of yeast Pic2 (Leary et al., 2009b; Vest et al., 2013; Baker et al., 2017; Boulet et al., 2018; Cobine et al., 2021). CuL in the matrix is finally translocated across the IMM to IMS by an unknown transporter to metalate SOD1 and COX (Leary et al., 2009b; Baker et al., 2017).

In the mitochondrial matrix, copper is present in much higher quantities than required for metalation of COX and SOD1, suggesting that the matrix copper pool would represent a storage reserve for delivery to the IMS (Cobine et al., 2004). The ability of the CuL to increase or decrease its size due to changes in cellular copper levels (Cobine et al., 2004) indicates that the $\mathrm{CuL}$ may be a dynamic regulator that responds to changes in cellular copper concentrations (Leary et al., 2009b). This function allows mitochondria to assure the presence of a constant supply and reserve of copper for metalation of their 
TABLE 1 | Copper binding and copper-dependent proteins key for the mitochondrial homeostasis.

\begin{tabular}{|c|c|c|c|}
\hline Protein & Function & Subcellular localization & References \\
\hline $\mathrm{Cu} / \mathrm{Zn}$ SOD (SOD1) & $\begin{array}{l}\text { Superoxide dismutase (SOD) catalyzes the reaction of superoxide } \\
\text { to hydrogen peroxide and requires copper and zinc as cofactors }\end{array}$ & Mitochondria, cytosol and nucleus & $\begin{array}{l}\text { McCord and Fridovich (1969); Yonashiro } \\
\text { et al. (2009); Mondola et al. (2016) }\end{array}$ \\
\hline $\begin{array}{l}\text { Cytochrome c } \\
\text { oxidase (COX) }\end{array}$ & $\begin{array}{l}\text { The terminal enzyme in the mitochondrial respiratory chain } \\
\text { catalyzes the reduction of dioxygen to water. Subunits } 1-3 \text { form } \\
\text { the functional core of the enzyme complex. COXI is the catalytic } \\
\text { subunit of the enzyme. Electrons originating in cytochrome c are } \\
\text { transferred via copper a center of subunit } 2 \text { and heme a of subunit } \\
1 \text { to the bimetallic center formed by heme A3 and copper B }\end{array}$ & Inner Mitochondrial Membrane & Kadenbach and Hüttemann (2015) \\
\hline $\operatorname{cox} 17$ & $\begin{array}{l}\text { Copper chaperone for COX. COX17 is a specific copper donor to } \\
\text { Sco1 and Cox11, which donate copper to the CuB and CuA sites } \\
\text { of cytochrome oxidase, respectively }\end{array}$ & $\begin{array}{l}\text { Mitochondrial Intermembrane } \\
\text { Space }\end{array}$ & Inesi (2016) \\
\hline $\mathrm{PIC2}$ & $\begin{array}{l}\text { A copper importer in the yeast mitochondrial matrix by the } \\
\text { mitochondrial carrier family (MCF). Orthologues in humans } \\
\text { SLC25A3 (copper/phosphate carrier protein, mitochondrial) }\end{array}$ & Inner Mitochondrial Membrane & Vest et al. (2013); Cobine et al. (2021) \\
\hline MRS3 & $\begin{array}{l}\text { Yeast iron transporter, involved in mitochondrial copper } \\
\text { homeostasis. Copper importer under copper-limiting conditions } \\
\text { or in the absence of Pic2. Orthologues in humans SLC25A37 } \\
\text { (mitoferrin-1) and SLC25A28 (mitoferrin-2) }\end{array}$ & Inner Mitochondrial Membrane & Vest et al. (2016) \\
\hline SCO1 & $\begin{array}{l}\text { Metallochaperones whose principal function is to add two copper } \\
\text { ions to the CuA site in the catalytic core of COX. There is a } \\
\text { functional connection between SCO1 and CTR1: the high-affinity } \\
\text { transporter that imports Cu into the cell. CTR1 degrades rapidly in } \\
\text { the absence of SCO1 protein, suggesting a posttranslational } \\
\text { mechanism to regulate CTR1-dependent Cu import into the cell } \\
\text { through SCO1 }\end{array}$ & Inner Mitochondrial Membrane & $\begin{array}{l}\text { Hlynialuk Christopher et al. (2015); } \\
\text { Morgada et al. (2015) }\end{array}$ \\
\hline SCO2 & $\begin{array}{l}\text { Metallochaperones whose principal function is to add two copper } \\
\text { ions to the CuA site in the catalytic core of COX. Copper- } \\
\text { dependent thiol reductase of the cysteine ligands in the oxidase. } \\
\text { Copper binding to Sco } 2 \text { is essential to elicit its redox function and } \\
\text { as a guardian of the reduced state of its cysteine residues in the } \\
\text { oxidizing environment of the mitochondrial intermembrane space }\end{array}$ & Inner Mitochondrial Membrane & Morgada et al. (2015) \\
\hline COA6 & $\begin{array}{l}\text { It is involved in the copper-dependent biogenesis of COX2. It can } \\
\text { bind copper and can associate with newly translated COX2 and } \\
\text { the mitochondrial copper chaperone SCO1 }\end{array}$ & $\begin{array}{l}\text { Mitochondrial intermembrane } \\
\text { space }\end{array}$ & $\begin{array}{l}\text { Stroud et al. (2015); Soma et al. (2019); } \\
\text { Pacheu-Grau et al. (2020) }\end{array}$ \\
\hline MIA40 & $\begin{array}{l}\text { Mitochondrial import and assembly protein, oxidoreductase of the } \\
\text { mitochondrial disulfide relay, catalyzes disulfide bond formation in } \\
\text { proteins in the IMS. By using copper-binding protein Cox17 as a } \\
\text { natural substrate. Ccs } 1 \text { shows interaction with Mia40. Mia40- } \\
\text { mediated oxidative folding of domain I of Ccs1 may control the } \\
\text { cellular distribution of Ccs } 1 \text { and, consequently, active SOD1 }\end{array}$ & $\begin{array}{l}\text { Mitochondrial intermembrane } \\
\text { space }\end{array}$ & $\begin{array}{l}\text { Klöppel et al. (2011); Koch and Schmid } \\
\text { (2014) }\end{array}$ \\
\hline PARK7 & Cu-dependent peptidase, function as a sensor of oxidative stress & $\begin{array}{l}\text { Mitochondria, nucleus, } \\
\text { endoplasmic reticulum and cytosol }\end{array}$ & $\begin{array}{l}\text { Björkblom et al. (2013); Blockhuys et al. } \\
\text { (2017) }\end{array}$ \\
\hline
\end{tabular}

biological targets, under different physiological processes (Leary et al., 2009b). The proper functioning of this signaling pathway also depends on proteins or secondary messengers that monitor and report the functional status of mitochondrial inner membrane proteins capable of sensing stimuli and transducing signals, such as copper-binding integral inner membrane proteins: COX11, SCO1, and SCO2 (Leary et al., 2009a; Leary et al., 2009b). Also, the COX assembly factors which are located in the IMS are soluble cysteine-rich proteins: COX17, COX19, COX23, and PET191 (Leary et al., 2009b). As a potential mechanism to stimulate OXPHOS metabolism, copper may directly act on the ETC to modulate the assembly or disassembly of respiratory complex IV. Indeed, complex IV serves as a metal sensor in the regulation of respiratory rates (Desler et al., 2012). Supporting this mechanism, copper deficiency reduces the expression and activity of complex IV (Dallman and Goodman 1970; Chen et al., 2002; Medeiros and Jennings 2002; Chen et al., 2005; Zeng et al., 2007; Ruiz et al., 2014), but not the other respiratory complexes (Zeng et al., 2007; Bustos et al., 2013). Regarding copper overload, the current results showed an increase in complex IV protein expression (Ruiz et al., 2016). Complex IV is made up of 11 protein subunits and requires 18 assembly factor proteins for accurate assembly (Koopman et al., 2012). A recent report showed that copper is able to rescue complex IV assembly in the mutant mouse deficient in the cytochrome assembly factor, COA6 (Ghosh et al., 2014). 


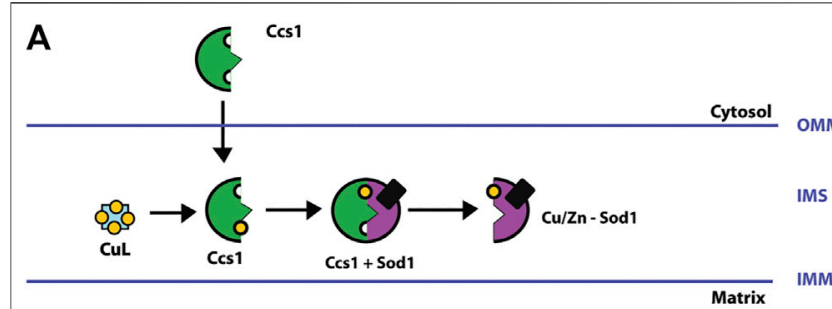

B

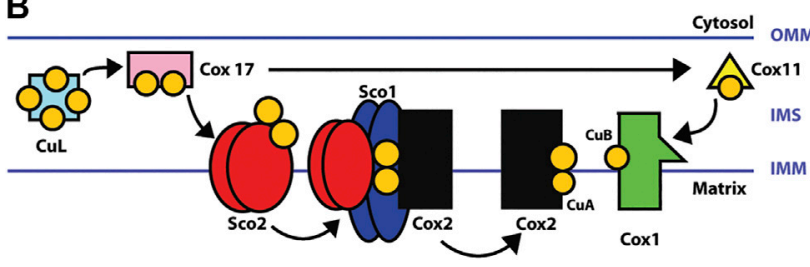

FIGURE 2 | (A) Schematic of Cu/Zn-SOD1 metalation in CCS1 mitochondria. CuL transfers a copper ion to CCS1 in the intermembrane space. The incorporation of zinc may be during or before metalation with copper by CCS1. SOD1 is metalated in the intermembrane space (IMS) of mitochondria and then enters the matrix (Cobine et al., 2006a; Cobine et al., 2006b; Robinson and Winge 2010; Fukai and Ushio-Fukai 2011). (B) Metalation of COX copper centers (CuA and CuB sites). COX is assembled in parts that are then merged to produce the matured holoenzyme complex. The COX1 subunit contains the CuB site, and the COX2 subunit, the CuA site. After entering mitochondria, CuL donates two copper ions to the copper chaperone COX17 which in turn transfers the copper ions to COX11 and SCO2. COX11 metalates the CuB site of the subunit COX1, and SCO2, the CuA site of subunit COX2 by delivering two copper ions in a SCO1-mediated process (Robinson and Winge 2010; Jett and Leary 2018).

Therefore, copper helps to assemble complex IV to respond to energy demands. More complex IV assembly will enhance other complex assemblies, as has been reported for complex I (Diaz et al., 2006).

Copper deficiency, on the other hand, interferes with COX biosynthesis, producing a decrease in mitochondrial ATP production, which causes remodeling of ETC complexes, represses respiration, and creates a reduction in the efficiency of oxygen utilization (Kopp et al., 1983; Bode et al., 1992; Zeng et al., 2007; Shoubridge 2012; Bustos et al., 2013; Ruiz et al., 2014; Jensen et al., 2019). It has been observed that as COX biosynthesis increases, other complexes tend to increase, such as complex I (Diaz et al., 2006). In our laboratory, we observed that there is a considerable increase of all ETC complexes by adding a noncytotoxic copper concentration to K562 cells (Ruiz et al., 2016).

\section{COPPER HAS A KEY ROLE IN CU/ZN SOD1 AND COX ASSEMBLY}

SOD enzymes have the primary responsibility for the dismutation of superoxide anions to hydrogen peroxide in cells. They have copper and zinc as a metal cofactor (SOD1 and SOD3), although there also exist variations with manganese in eukaryotes (SOD2) and with iron and nickel in bacteria and protists. In humans,

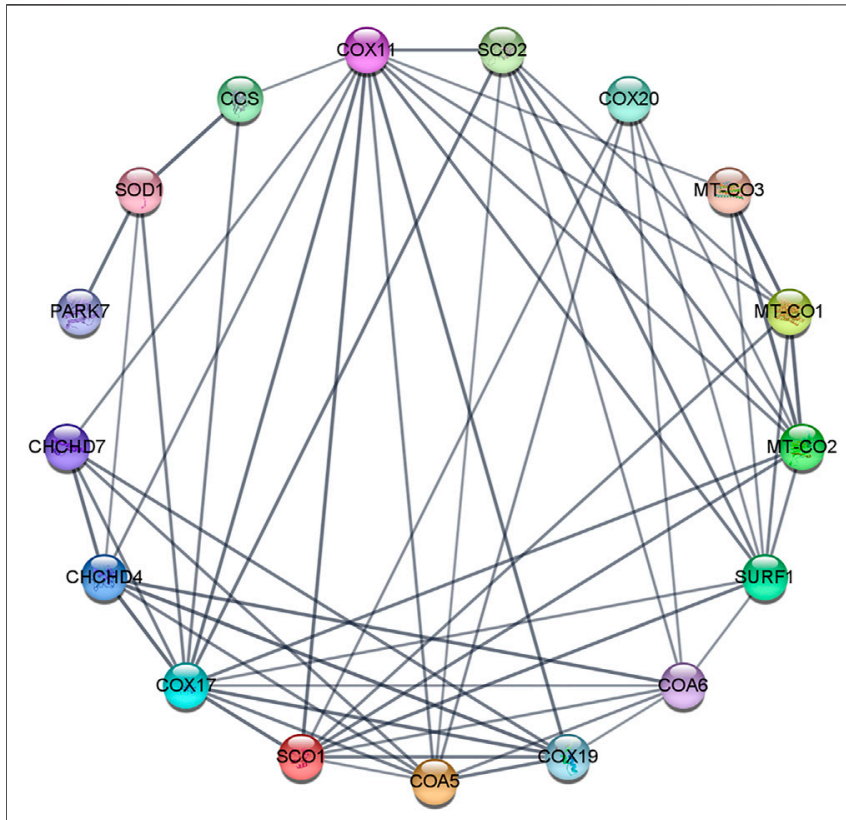

SLC25A37 SLC25A28 SLC25:3

FIGURE 3 | Copper protein network in mitochondria-STRING interaction network. The interaction network was created with the STRING (Search Tool for the Retrieval of Interacting Genes/Proteins) database version 11.0. A medium confidence cutoff of 0,7 was implemented in this work. The resulting protein association network for copper was visualized by a Cytoscape v3.8.2. Proteins are presented as nodes (circles) connected by lines (Edge) whose thickness represents the strength of the connection based on the STRING database. For example, in the network's inferior part, three nodes ("SLC25A28," "SLC25A37," and "SLC25A37") are not connected to the network. The node "CCS" is connected to "COX11," "COX17," and "SOD1" nodes. The edge (line) that connected "CCS" with "SOD1" is thicker than the edge between "CCS" and "COX11," and nodes (shared named, Stringdb canonical name, display name, neighborhood connectivity - number of neighbors). COX17 (9606. ENSP00000261070, Q14061, COX17, 7); COX11 (9606. ENSP00000299335, Q9Y6N1, COX11, 7); SURF1 (9606. ENSP00000361042, Q15526, SURF1, 8); PET191 (9606. ENSP00000330730, Q86WW8, COA5, 8); SCO1 (9606. ENSP00000255390, O75880, SCO1, 8); MT-CO2 (9606. ENSP00000354876, P00403, MT-CO2, 8); COA6 (9606. ENSP00000355572, Q5JTJ3, COA6, 8); MIA40 (9606. ENSP00000295767, Q8N4Q1, CHCHD4, 8); COX19 (9606. ENSP00000342015, Q49B96, COX19, 9); SCO2 (9606. ENSP00000444433, O43819, SCO2, 9); MT-CO1 (9606. ENSP00000354499, P00395, MT-CO1, 9); COX23 (9606. ENSP00000306425, Q9BUKO, CHCHD7, 8); COX20 (9606. ENSP00000406327, Q5RI15, COX20, 9); SOD1 (9606. ENSP00000270142, P00441, SOD1, 9); MT-CO3 (9606. ENSP00000354982, P00414, MT-CO3, 9); CCS (9606. ENSP00000436318, O14618, CCS, 6); PARK7 (9606. ENSP00000418770, Q99497, PARK7, 4); SLC25A3 (9606.

ENSP00000228318, Q00325, SLC25A3, 0); SLC25A28 (9606. ENSP00000359526, Q96A46, SLC25A28, 0); and SLC25A37 (9606. ENSP00000429200, Q9NYZ2, SLC25A37, 0). In Supplementary Material additional data of the copper protein interaction network can be found.

there are three isoforms, that is, SOD1, SOD2, and SOD3. SOD1 is mostly located in the cytosol, but $5-10 \%$ can be found in the mitochondria. SOD2 localizes in the mitochondrial matrix and SOD3 in the extracellular fluid. Although SOD2 is the 
predominant superoxide dismutase in the mitochondrial matrix, SOD1 is critical to the control of oxidative stress in the mitochondrial intermembrane space (Zelko et al., 2002; Fukai and Ushio-Fukai 2011). The relevance of the antioxidant proteins and SODs is given by the control of ROS, which are known to regulate cell signaling (Wang et al., 2018).

SOD1 is a homodimer having a binuclear copper and zinc site in each subunit, which forms a narrow channel where the dissociation of $2 \mathrm{O}_{2}{ }^{-}$to $\mathrm{H}_{2} \mathrm{O}_{2}$ is carried out (Rhee et al., 2005). SOD1 is mostly metalated in the cytosol and remains in the cytosol. However, mitochondria-targeted SOD1 must first enter as an apoprotein (without copper) to be metalated in the IMS by CCS1 (Cobine et al., 2006a). CCS1 is a small polypeptide with three domains; domains 1 and 3 bind copper, while domain 2 is the key to the interaction with SOD1 (Lamb et al., 2000). The transient interaction is mediated by domains 2 and 3 of CCS1 (Robinson and Winge 2010). Figure 2 shows the place where CuL delivers copper to CCS1 inside the mitochondria.

COX is the terminal enzyme of the ETC and catalyzes the reduction of oxygen to water. It consists of 13 subunits. COX1 (MT_CO1), COX2 (MT-CO2), and COX3 are encoded in the mitochondrial DNA and form the COX catalytic center. The nuclear genome encodes the remaining ten subunits. The catalytic center of the enzyme contains 3 copper ions located in 2 copper centers, 2 copper ions in the CuA center, and 1 in the $\mathrm{CuB}$ center. Furthermore, two heme groups ( $\alpha$ and $\alpha 3$ ) are also needed. The catalytic core is responsible for the oxidation of cytochrome $\mathrm{c}$ and the reduction of oxygen to water (Horn and Barrientos 2008; Leary et al., 2009b).

COX17 initiates the copper transfer reactions for COX metalation in the IMS, which acquires copper from the CuL and requires additional COX11, SCO1, SCO2, and COA6. COX11 metalates the CuB site in COX1, and SCO1, SCO2, and COA6 metalate the $\mathrm{CuA}$ site in COX2. Once copper redox cofactors and heme groups are added into COX1 and COX2, the remaining subunits are added for final maturation (Figure 2) (Jett and Leary 2018; Robinson and Winge 2010). COA6 enables COX biogenesis as a thiol-reductase for copper to reduce disulfide bridges of critical cysteine residues in SCO1 and SCO2 metallochaperones in mitochondria (Pacheu-Grau et al., 2020; Soma et al., 2019). In this review, we analyzed the protein-protein interactions (PPIs) of the copper network in mitochondria with the Search Tool for the Retrieval of Interacting Genes/Proteins (STRING). The PPI network consisted of 20 nodes and 57 edges. The neighborhood connectivity of the nodes has an average of 7 neighbors (Figure 3). The interaction network shows that assembly and copper metalation of COX and SOD1 in mitochondria are very intricate. When COX1 is inserted in the mitochondrial membrane, SURF1 adds the heme group into COX1, and COX11 facilitates the formation of the $\mathrm{CuB}$ site. Copper for $\mathrm{CuB}$ is donated to COX11 by COX17 at the COX11 binding site right after cysteine sulfides are reduced by COX19. On the other hand, COX2 facilitates the maturation of the $\mathrm{CuA}$ site when it is bound to a protein complex composed of COX20, COA6, SCO1, and SCO2. Copper is required to be transferred from COX17 to SCO1 where the oxidoreductase activity of SCO2 on COX2 cysteine is considered fundamental. Likewise, these reactions are associated with COA6 which reduces COX2 and SCO1, allowing copper binding (Cobine et al., 2021). The network suggests that the interaction of COA6 with COX17, SURF1, SCO1, SCO2, and MIA4 (CHCHD4) appears to be the entry point for cysteine-containing chaperones such as COA6, COX17, and COX19.

\section{ROLE OF COPPER ON MITOCHONDRIA AND CELL FATE DETERMINATION}

Hematopoietic stem cells (HSCs) and their fate are highly dependent on the mitochondrial metabolism. Mitochondria are responsible for metabolic reprograming needed for the commitment and differentiation of HSCs into different cell lineages, beyond energy production. In erythropoiesis, mitochondria are also involved in heme and hemoglobin biosyntheses (Fontenay et al., 2006; Kim et al., 2008; Chung et al., 2012). Typical mammalian HSCs remain quiescent in the hypoxic zone of the bone marrow (endosteal niche) to favor selfrenewal, a process governed by the stabilization of the hypoxiainducible factor-1 alpha (HIF-1 $\alpha$ ) protein and consequent heterodimerization with HIF-1ß to activate transcription in many target genes, including glycolytic enzymes (Takubo et al., 2010). Thus, HSCs and embryonic stem cells have a minimal basal metabolism relying mainly on glycolysis, while mitochondrial respiration is low to avoid the generation of reactive oxygen species (ROS) (Zhang et al., 2011; Xu X. et al, 2013; Bigarella et al., 2014). Transition from glycolysis to OXPHOS and then from self-renewal to differentiation is dependent on the presence of oxygen (Piccoli et al., 2005; Piccoli et al. 2006; Piccoli et al. 2013), mitochondrial respiratory substrates (Zhang et al., 2011; Vozza et al., 2014), and the generation of mitochondrial ROS (Maryanovich and Gross 2013; Bigarella et al., 2014). Furthermore, the participation of mitochondrial fusion and fission events, the so-called mitochondrial dynamics (MtDy) (Wanet et al., 2015; Luchsinger et al., 2016; Gonzalez-Ibanez et al., 2020), and the mitochondrial permeability transition pore (mPTP) (Folmes et al., 2012) have been involved in this metabolic reprogramming.

Since respiratory complex IV has two copper sites that are essential for its function, its activity can be easily manipulated by either copper removal/chelation or copper overload, affecting the overall purpose and assembly of the ETC. Thus, managing the cellular copper level seems a simple way for metabolic reprograming switching from glycolysis to OXPHOS, and vice versa, to control cell fate. In this regard, copper imbalances cause anemia, neutropenia, thrombocytopenia (decreased blood platelets), myelodysplastic syndrome, and leukemia due to alterations in the differentiation process of the hematopoietic progenitor cells (Zidar et al., 1977; Goyens et al., 1985; Hirase et al., 1992; Gregg et al., 2002; Fong et al., 2007; Halfdanarson et al., 2008; Griffith et al., 2009; Gletsu-Miller et al., 2011; Gabreyes et al., 2013). In hematopoietic stem cells (HSCs), low copper delayed differentiation and stimulated cell expansion. 
Since the lack of copper promotes cell expansion, it has been proposed to be useful for ex vivo stem cell expansion which is yearned for cell therapy (Peled et al., 2002; Huang et al., 2009; Dahlberg et al., 2011). At the mitochondrial level, the use of copper chelators results in decreased COX levels and mitochondrial and cellular ROS levels, the activation of glycolysis, and the appearance of giant mitochondria in erythropoietic cell lines and primary EPO-induced CD34 ${ }^{+}$cell differentiation (Dallman and Goodman 1970; Wakabayashi et al., 1975; Kim et al., 2010; Bustos et al., 2013; Ruiz et al., 2014; Jensen et al., 2019). This metabolic change could allow their survival and cellular proliferation while awaiting the ideal conditions to continue their differentiation (Bustos et al., 2013; Jensen et al., 2019). Copper deficiency alters metabolic reprogramming in differentiating HSCs, reversing to an immature phenotype related with erythroid progenitor cell expansion, with low oxygen consumption, low ROS generation, and high membrane potential (Jensen et al., 2019). In addition, copper deficiency has been associated with increased expression of the mitochondrial fusion proteins such as MFN1, MFN2, and OPA1 (optic atrophy 1) (Yoon et al., 2003; Chang and Blackstone 2010), and increased mitochondrial membrane potential in K562 and EPOinduced CD34 ${ }^{+}$cells (Bustos et al., 2013; Jensen et al., 2019). In our laboratory, we generated a model of copper deficiency in C57 black mice with a BCS treatment that showed mild signs of anemia (Ruiz et al., 2014) and reduced the expression of ceruloplasmin, ATP7B, and CIV, as previously reported by other groups (Liebes and Medeiros 1997; Medeiros et al., 1997; Rossi et al., 1998; Cerone et al., 2000; Getz et al., 2011; Gupta et al., 2011; Lassi and Prohaska 2012; Ruiz et al., 2014). Also, the BCS-treated mice had more oxidized proteins, upregulation of the MFN2 protein, OXPHOS remodeling from supercomplexes to individual complexes, and higher oxygen consumption rates (Ruiz et al., 2014). Besides, the liver showed large mitochondria with a mix of average, balloon, and butternut squash mitochondria (Ruiz et al., 2014). The butternut squash mitochondria showed features between normal and swollen mitochondria, which are likely an intermediate state between the two phenotypes (Ruiz et al., 2014). It has also been reported that copper depletion with TEPA (tetraethylenepentamine) favored the maintenance and expansion of HSCs for erythroid differentiation (Huang et al., 2009).

On the other hand, individuals with high levels of copper in their blood showed altered hematological parameters with an increased number of proerythroblasts (early stage of erythropoietic differentiation) and a decreased number of orthochromatophilic erythroblasts (advanced phase of erythropoietic differentiation) (Gregory and Eaves 1978). High copper content has been associated with hemolysis because of its direct effect on the ETC and increased generation of oxidative stress (Fibach and Rachmilewitz 2008; Ruiz et al., 2016). This could trigger a compensatory mechanism by accelerating the erythropoietic process and releasing immature cells into the

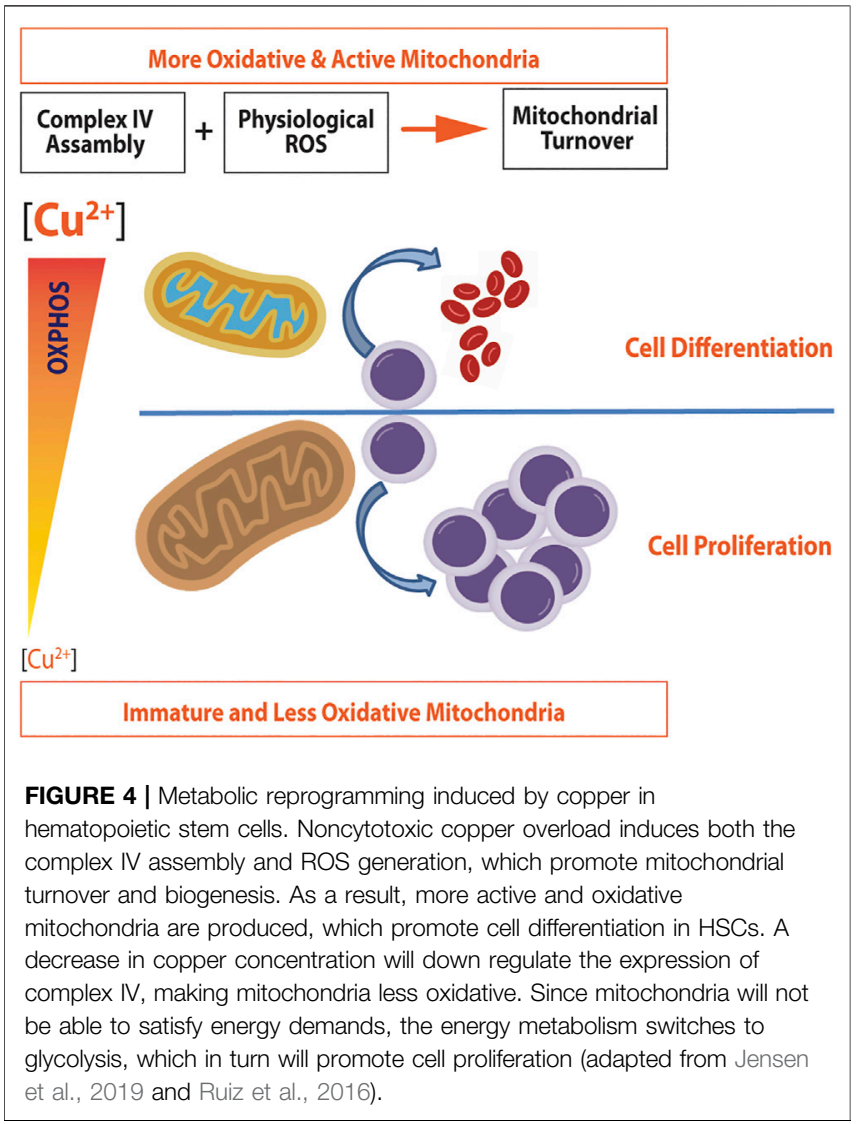

bloodstream (Wagner et al., 2000). High copper levels are then associated with mitochondrial dysfunction and cell death. However, noncytotoxic copper overload has been described to improve mitochondrial function by stimulating the biogenesis and assembly of complex IV along with the generation of a physiological amount of ROS in the erythropoietic cell line K562. This process stimulated mitochondrial turnover by mitophagy and mitochondrial biogenesis, resulting in highly active mitochondria overpacked with OXPHOS proteins for ATP synthesis (Ruiz et al., 2016). Thus, physiological ROS generation has been considered an adaptive response to produce adjustments in signaling pathways related to proliferation, metabolic adaptation, cell motility, adaptations to hypoxia, and angiogenesis (Wang et al., 2018).

Cellular copper levels, either in excess or lack, altered mitochondrial function in stem cells and many other cell types having an impact on either proliferation or differentiation. Figure 4 represents the metabolic reprogramming of HSCs toward expansion or differentiation according to intracellular copper levels. A lack of copper will induce cell expansion, a noncytotoxic copper overload, and differentiation. Furthermore, Tables 2, 3 show several primary cells and cell lines that have been exposed to different copper concentration or chelators and assayed for cell proliferation or differentiation. 
TABLE 2 | Effect of copper increase on proliferation and differentiation in different cell types.

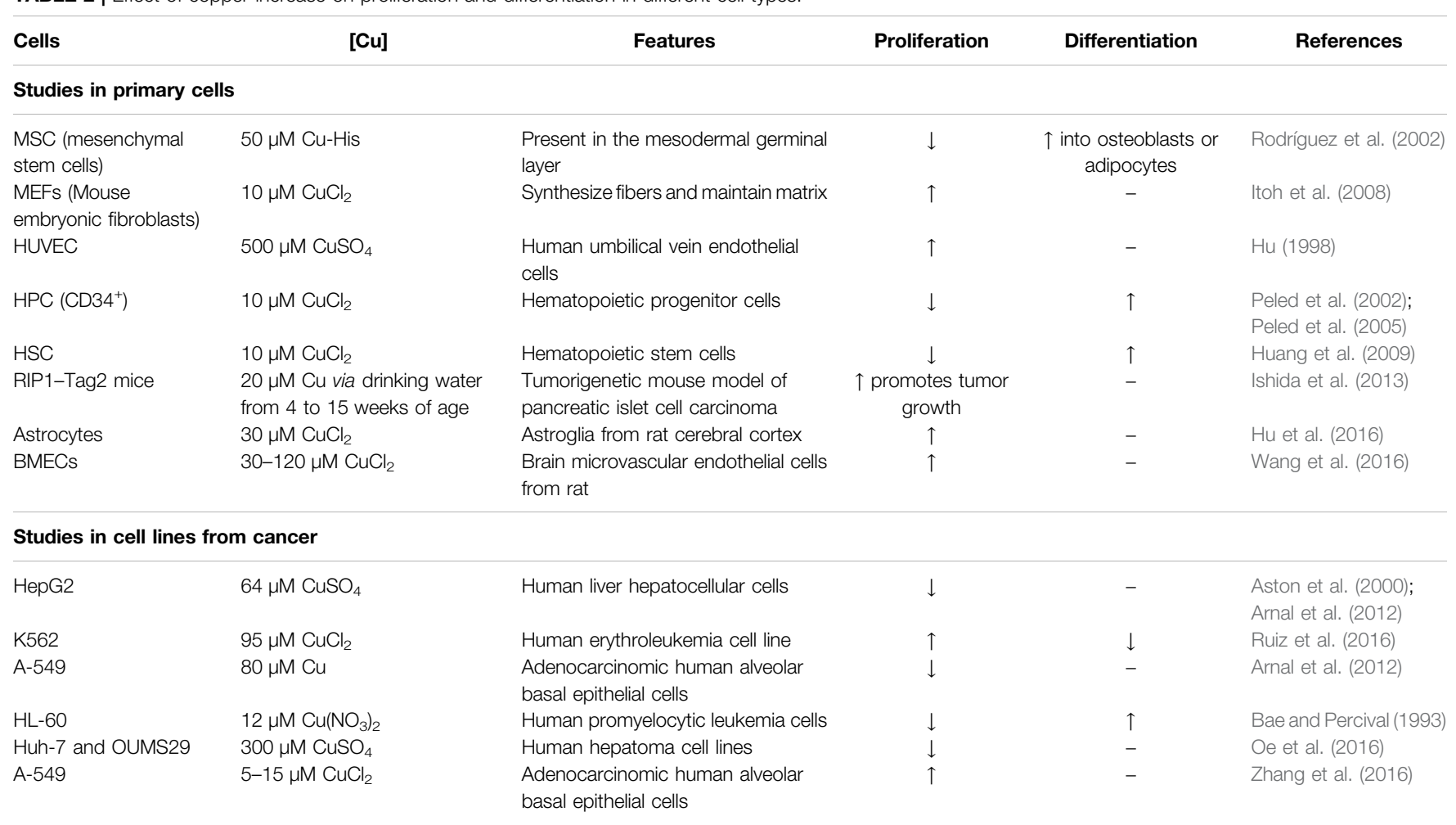

$\uparrow$ : increase; $\downarrow$ : decrease.

\section{COPPER ROLE IN CANCER}

Metabolic reprogramming can go from differentiated to proliferative cells as it happens in cancer cells and induced pluripotent stem cells (iPSCs), where the cell metabolism switches from OXPHOS to aerobic glycolysis (Warburg effect). Regarding mitochondria in cancer cells, they displayed a stem cell-like phenotype, that is, low oxygen consumption and low ROS, although they displayed higher membrane potential than healthy cells (Bonnet et al., 2007; Hanahan and Weinberg Robert 2011; Schulze and Harris 2012; Wanet et al., 2015).

The remarkable change in the metabolism that occurs in cancer cells has been associated, among other factors, with the management of copper and proteins that use it (Gupte and Mumper 2009). An example of this is obtained by observing the high levels of ceruloplasmin found in various forms of cancer, such as lymphomas, breast cancer, and gastrointestinal cancer (Scanni et al., 1977; Ungar-Waron et al., 1978; Linder and Roboz 1986; Gupte and Mumper 2009), and ceruloplasmin levels have been found to be increased 4 to 8 times during malignant progression, returning to normal levels after tumor regression (Brem et al., 1990; Brem 1999). Copper levels increase three times in blood plasma, relating to tumor burden, progression, incidence, invasion, and reoccurrence of the disease (Goodman et al., 2004; Gupte and Mumper 2009). The human $\mathrm{Cu}$ proteome, with $54 \mathrm{Cu}$-binding proteins, are up- or downregulated in 18 cancer types (thymus, head and neck, esophagus, adrenal gland, bladder, stomach, soft tissue, kidney, pancreas, bile duct, liver, prostate, cervix, breast, uterus, thyroid, colorectal, and lung), showing intricate patterns (Blockhuys et al., 2017).

Angiogenesis is the development of new blood vessels which are required for tumor growth (Folkman and Klagsbrun 1987). Cancer cells have developed ways to synthesize and release their own angiogenic stimulants or to recruit endothelial cells for the same purpose (Goodman et al., 2004; Lowndes and Harris 2004; Lowndes and Harris 2005; Gupte and Mumper 2009).

Copper is a potent stimulator of the angiogenic process by the activation of angiogenic factors like the interleukin (IL)-1, IL-6, and IL-8; tumor necrosis factor alpha (TNF- $\alpha$ ); angiogenin; the basic fibroblast growth factor (bFGF); fibronectin; and the vascular endothelial growth factor (VEGF), which are critical for tumor angiogenic developments (Li 2020). Copper sulfate $\left(\mathrm{CuSO}_{4}\right)$ combined with increasing doses of VEGF or FGF-2 revealed synergistic effect in endothelial cells grown in a $3 \mathrm{D}$ culture system with enhanced collagen fiber deposition providing complexity of angiogenic networks (Gérard et al., 2010). Coppercoated disks inserted subcutaneously in rats stimulated a high and extended-release of interleukin-1 $1 \alpha$ (IL-1 $\alpha$ ) and low quantities of IL- $1 \beta$ by recruited cells (Suska et al., 2003). HIF-1 transcriptional activity requires the accumulation of HIF- $1 \alpha$ following inhibition of prolyl hydroxylases. This inhibition is generated by hypoxia, and chemical hypoxia can be generated by cobalt. Copper chelation with tetraethylenepentamine alters the transcriptional activity of HIF-1 $1 \alpha$, decreasing the mRNA and protein expression of VEGF, which is rescued by $25 \mu \mathrm{M}$ CuSO4. Also, CCS1 gene 
TABLE 3 | Effect of copper decline on proliferation and differentiation in different cell types.

\begin{tabular}{|c|c|c|c|c|c|}
\hline Cells & [Chelator] & Features & Proliferation & Differentiation & References \\
\hline \multicolumn{6}{|c|}{ Studies in primary cells } \\
\hline Human fibroblast & $\begin{array}{l}100 \mu \mathrm{M} \text { D-penicillamine and } 8 \mu \mathrm{M} \\
\mathrm{CuSO}_{4}\end{array}$ & $\begin{array}{l}\text { Synthesize fibers and maintain the } \\
\text { extracellular matrix of tissues }\end{array}$ & $\downarrow$ & - & $\begin{array}{l}\text { Matsubara and } \\
\text { Hirohata (1988); } \\
\text { Goodman et al. (2004) }\end{array}$ \\
\hline HSC & $40 \mu \mathrm{M}$ Tepa & Hematopoietic stem cells & $\uparrow$ & $\downarrow$ & Huang et al. (2009) \\
\hline HPC & $40 \mu \mathrm{M}$ Tepa & Hematopoietic progenitor cells & $\uparrow$ & $\downarrow$ & $\begin{array}{l}\text { Peled et al. (2002); } \\
\text { Peled et al. (2005); } \\
\text { Huang et al. (2009) }\end{array}$ \\
\hline $\begin{array}{l}\text { CD34 }{ }^{+} \\
\text {hematopoietic stem } \\
\text { cells }\end{array}$ & $\begin{array}{l}10,20 \text {, or } 30 \mu \mathrm{M} \text { BCS during } 6 \text { days of } \\
\text { culture } 1 \times 10^{-4} \% \text { or } 5 \times 10^{-4} \% \text { sodium } \\
\text { azide during } 6 \text { days of culture }\end{array}$ & $\begin{array}{l}\text { HSC possesses multipotentiality, } \\
\text { enabling them to self-renew and to } \\
\text { produce mature blood cells, such as } \\
\text { erythrocytes, leukocytes, platelets, } \\
\text { and lymphocytes }\end{array}$ & $\uparrow$ & $\downarrow$ & Jensen et al. (2019) \\
\hline Lymphocyte T & $\begin{array}{l}25 \mu \mathrm{g} / \mathrm{ml} \mathrm{D} \text { - penicillamine and } 2 \mu \mathrm{g} / \mathrm{ml} \\
\mathrm{CuSO}_{4}\end{array}$ & Immune system cell & $\downarrow$ & - & $\begin{array}{l}\text { Lipsky and Ziff (1980); } \\
\text { Lipsky (1984) }\end{array}$ \\
\hline HUVEC & Inhibition of Cu transporter Ctr1 & Human umbilical vein endothelial cells & $\downarrow$ & $\uparrow$ & $\begin{array}{l}\text { Narayanan et al. } \\
(2013)\end{array}$ \\
\hline RIP1-Tag2 mice & $\begin{array}{l}\text { Tetrathiomolybdate } 1 \mathrm{mg} \text { daily for up to } \\
3 \text { weeks }\end{array}$ & $\begin{array}{l}\text { Tumorigenetic mouse model of } \\
\text { pancreatic islet cell carcinoma }\end{array}$ & $\downarrow$ & $\begin{array}{l}\downarrow \text { reduction in the } \\
\text { number of } \\
\text { angiogenic islets }\end{array}$ & Ishida et al. (2013) \\
\hline$\beta$ ТС3 & $10 \mu \mathrm{M}$ tetrathiomolybdate & Derived from RIP1-Tag2 tumors & $\downarrow$ & - & Ishida et al. (2013) \\
\hline Tumor endothelia & $\begin{array}{l}\text { Penicillamine ( } 2000 \mu \mathrm{g} \text { per dose per } \\
\text { mouse) Trientine ( } 700 \mu \mathrm{g} \text { per dose per } \\
\text { mouse) }\end{array}$ & $\begin{array}{l}\text { Derived from mesothelioma tumors in } \\
\text { mice }\end{array}$ & $\downarrow$ & - & Crowe et al. (2013) \\
\hline A549 xenograft & Curcumin (U0126) & Tumor xenograft model & $\downarrow$ & - & Zhang et al. (2016) \\
\hline \multicolumn{6}{|c|}{ Studies in cell lines from cancer } \\
\hline K562 & $10 \mu \mathrm{M}$ BCS & Human erythroleukemia cell line & $\downarrow$ & $\downarrow$ & Bustos et al. (2013) \\
\hline $\begin{array}{l}\text { 9L Gliosarcoma rat } \\
\text { model }\end{array}$ & $\begin{array}{l}2 \text { mg D- penicillamine orally, once daily, } \\
\text { on the } 3 \text { days before and after } \\
\text { implantation }\end{array}$ & Brain Glial cell & $\downarrow$ & - & Yoshida et al. (1995) \\
\hline U937 & $5 \mu \mathrm{mol} / \mathrm{L}$ tet $(2,3,2$-tetraamine $)$ & Human promonocytic cells & $\downarrow$ & $\downarrow$ & $\begin{array}{l}\text { Huang and Failla } \\
(2000)\end{array}$ \\
\hline A2780 & $10 \mu \mathrm{M}$ tetrathiomolybdate & Human ovarian carcinoma cells & $\downarrow$ & - & Ishida et al. (2013) \\
\hline A375 & Sulfur nanoparticles (Nano-S) & Malignant melanoma & $\downarrow$ & - & Liu et al. (2016) \\
\hline MCF-7 & Nano-S & Breast cancer cells & $\downarrow$ & - & Liu et al. (2016) \\
\hline H1299 & $\begin{array}{l}\text { DC_AC2, DC_AC30, DC_AC49, } \\
\text { DC_AC50, DC_AC61, DC_AC71 }\end{array}$ & Lung cancer cells & $\downarrow$ & - & Wang et al. (2015) \\
\hline $212 L N$ & $\begin{array}{l}\text { DC_AC2, DC_AC30, DC_AC49, } \\
\text { DC_AC50, DC_AC61, DC_AC71 }\end{array}$ & Head and neck cancer cells & $\downarrow$ & - & Wang et al. (2015) \\
\hline MB231 & $\begin{array}{l}\text { DC_AC2, DC_AC30, DC_AC49, } \\
\text { DC_AC50, DC_AC61, DC_AC71 }\end{array}$ & Breast cancer cells & $\downarrow$ & - & Wang et al. (2015) \\
\hline
\end{tabular}

$\uparrow$ : increase; $\downarrow$ : decrease.

silencing blocked VEGF expression, revealing copper requirement for cobalt-activated transcriptional activity of HIF-1 $\alpha$ in promoting the expression of VEGF (Qiu et al., 2012). Angiogenin-bound copper is a strong inducer of bloodvessel development, and it binds to endothelial cell receptors and extracellular matrix components (Soncin et al., 1997). In vitro, copper sulfate incubation stimulates human umbilical vein endothelial cell proliferation and migration ( $\mathrm{Hu}$ 1998). In vitro, copper salts could induce the synthesis of the fibronectin matrix associated with angiogenesis (Kochi et al., 1983; Gullino 1986). The study of the mechanism of angiogenesis in the adult organism, through a rabbit cornea model, implanted with $10-75^{\circ} \mu \mathrm{g}$ of copper sulfate pellets in the corneal stroma, induced long-lasting and dose-dependent neovascularization, showed that copper directly stimulates angiogenesis, and it is helpful in the evaluation of antiangiogenic agents (Parke et al., 1988). The expression of some angiogenic growth factors and cytokines is reduced when copper levels are decreased (Brem et al., 1990; Brem 1999). Cerebral neoplasms sequester copper, utilizing a rabbit brain tumor model, and showed that normocupremic animals formed big vascularized VX2 carcinomas, while in copper depleted by diet- and penicillamine (CDPT)-treated rabbits, the tumors developed were small, circumscribed, and relatively avascular. Metabolic and pharmacologic removal of copper overcomes cerebral tumor angiogenesis (Brem et al., 1990).

With these antecedents, the concept of antiangiogenic therapies as cancer treatments has begun, although a phase two trial of copper depletion by diet and penicillamine as antiangiogenic therapy of glioblastoma multiforme did not 
improve survival in patients (Brem 1999; Brem et al., 2005). Since it was discovered that tumor development is dependent on the formation of new blood vessels, the mechanisms that regulate angiogenesis continue to be investigated (Tisato et al., 2010).

Many angiogenic promoters appear to be dependent on copper concentrations. They control various endogenous stimulators by acting as a cofactor, leading to the use of copper chelators as therapeutic strategies with antiangiogenic function. The most used copper chelators in tests are D-Pen (D-penicillamine) and TM (tetrathiomolybdate). D-Pen is an effective copper chelator and has antiangiogenic properties. In addition, it can inhibit essential growth factors (VEGF and FGF), requiring copper as a cofactor (Brem et al., 1990; Brem 1999; Gupte and Mumper 2009). However, in the phase two trial, twomonth treatment with a copper-deficient diet combined with D-pen as antiangiogenic therapy for glioblastoma did not significantly increase the patients' survival, despite effective hypocupremia (Brem et al., 2005).

On the other hand, trials in rodents showed that by decreasing copper levels using TM, there was a sharp decrease in angiogenesis (Brewer 2001). A phase two trial with TM in patients with advanced kidney cancer concluded that this treatment was well tolerated, decreased copper concentrations in all patients, and that $31 \%$ of patients showed stability in the disease for at least 6 months (Redman et al., 2003). TM reduces the secretion of IL-6 and bFGF by head and neck SCC (HNSCC) cell lines in vitro. Also, in a rat aortic ring assay, the HNSCC cell lines treated with TM decreased endothelial cell chemotaxis, tubule formation, and neovascularization (Teknos et al., 2005). TM induced mild copper deficiency in the phase I clinical trial in patients with metastatic cancer treated with a dose of $120 \mathrm{mg} /$ day, followed by ceruloplasmin decrease to $20 \%$ baseline without toxicity (Brewer et al., 2000). Then, a phase II clinical trial in patients with malignant pleural mesothelioma received TM at $180 \mathrm{mg} /$ day, starting 4-6 weeks post-surgery for 15 months. After 34 days, this dosage decreased ceruloplasmin levels from $45 \mathrm{mg} / \mathrm{dl}$ to $13 \mathrm{mg} / \mathrm{dl}$. This mild copper deficiency decreases VEGF levels in the serum from an average of 2086 to $1,250 \mathrm{pg} /$ $\mathrm{ml}$, and patients showed encouraging results about overall survival (Pass et al., 2008). There must be several mechanisms by which the decrease of copper using TM inhibits tumor angiogenesis. For example, TM-treated SUM149 (inflammatory breast cancer cell line) cells released significantly lower amounts of 5 angiogenic factors (VEGF, FGF, IL1, IL6, and IL8) than untreated cells. TM has also shown to inhibit endothelial cell differentiation and to suppress $\mathrm{NF \kappa B}$ protein levels and its transcription (NFkB is known to regulate many genes involved in tumor invasion, angiogenesis, and metastasis) (Pan et al., 2002; Brewer 2003; Brewer et al., 2003).

In the murine HCC (human hepatocellular carcinoma) xenograft model, tumor development and angiogenesis were suppressed by trientine, a copper-chelating agent. Trientine treatment in combination with a copper-deficient diet caused a noticeable inhibition of neovascularization and increased apoptosis in the HCC tumor (Yoshii et al., 2001).

The depletion of mitochondrial copper induces a metabolic reprogramming that shifts from oxidative to glycolytic metabolism and reduces energy production. The above is an effective therapy against cancer types that depends on OXPHOS. Copper-depleting nanoparticle (CDN) targeted on mitochondria causes a metabolic shift from respiration to glycolysis in triplenegative breast cancer (TNBC). CDNs are composed by a copperdepleting moiety (CDM) and a semiconducting polymer nanoparticle (SPN). The CDM is composed of N,N-Bis (2pyridinylmethyl)-1,2-ethanediamine linked to tricarbocyanine. SPN consists of semiconducting polymers and phospholipidpolyethylene glycol (PEG). CDN administration inhibits tumor growth and improves survival of three mouse models of TNBC (Cui et al., 2021).

Abnormal copper accumulation in cancer cells can help to distinguish transformed cells from healthy ones and can be used as targets for novel chemotherapeutic agents (Daniel et al., 2004), such as the use of organic copper compounds in antitumor treatments has been investigated as cytotoxic agents and showed antitumor activity, such as $\mathrm{Cu}$ (II) thiosemicarbazide complexes, Isatin-Schiff base $\mathrm{Cu}(\mathrm{II})$ complexes [(4,7-dimethyl1,10-phenanthroline) (glicinate)], $\mathrm{Cu}$ (II) nitrate complex, Casiopeina II-gly, and imidazole, benzimidazole, and pyrazole $\mathrm{Cu}$ (II) complexes. The mode of action of these compounds is through producing high levels of ROS, mitochondrial toxicity, and DNA interactions, inhibiting cell proliferation and producing apoptosis. For example, Casiopeínas ${ }^{\circledR}$ are mixed chelate copper (II) compounds $([\mathrm{Cu}(\mathrm{N}-\mathrm{N})(\mathrm{O}-\mathrm{O})] \mathrm{NO} 3$ or $[\mathrm{Cu}(\mathrm{N}-\mathrm{N})(\mathrm{O}-\mathrm{N})]$ NO3) with antitumor potential. Casiopeínas ${ }^{\circledR}$ alter mitochondria bioenergetics, with reports of inhibition of respiration and ATP synthesis, mitochondrial swelling, loss of mitochondrial membrane potential, and cytochrome $c$ release (Ruiz-Azuara and Bravo-Gomez 2010). Another example of this is found in the use of D-Pen together with cupric sulfate. This mixture was able to cause a dose-dependent cytotoxicity in human cancer cells. (Gupte and Mumper 2009).

Cancer cells are sensitive to proteasome inhibition, suggesting good potential as anticancer agents for copper complexes (Zuo et al., 2013). Amino acid Schiff base-copper (II) complexes inhibit the chymotrypsin-like activity of the proteasome, producing a buildup of proteasome target proteins Bax and I $\mathrm{B}-\alpha$, therefore inducing growth inhibition and apoptosis. Cyclic dithiocarbamate (DTC) ligands, such as the neutral $\mathrm{Cu}$ (II) derivatives of the type [Cu(DTC)2], show remarkable anticancer activity (IC50 $\leq 1 \mu \mathrm{M})$ (Brustolin et al., 2018). Cu(II) ion increases the activity of 8-hydroxyquinoline derivatives in inhibiting the chymotrypsin-like activity of the proteasome and induces growth inhibition and apoptosis (Oliveri et al., 2017). The $\mathrm{Cu}(\mathrm{II})$ ion complex with glycoconjugate DTC shows potential applications in targeted chemotherapy; in particular, the CuGlu ([CuII(DTC- $\beta$-D-glucose)2]) revealed an exciting IC50 $(2.0 \pm 0.1 \mu \mathrm{M})$ value for the HCT116 human colorectal carcinoma cell line (Pettenuzzo et al., 2019). Estrogenfunctionalized $\mathrm{Cu}$ (II) complexes are potent anticancer agents with low IC50 values. Their cellular uptake occurred via passive diffusion, and their mechanisms involved high DNA intercalation, intense DNA 
cleaving activity, and stimulation ROS production (Barrett et al., 2020). [Cu(L-proline methyl ester DTC)2] copper compounds into micelles with a cancer-targeting biomolecule are presented as a proper "Trojan Horse" strategy for the delivery of Cu-DTC chemotherapeutics (Brustolin et al., 2020).

\section{MECHANISMS OF COPPER ACTION ON TUMOR DEVELOPMENT}

It has been shown that exposure to high levels of copper in water ( $1.3 \mathrm{mg} / \mathrm{L}$ maximum levels allowed in public water supplies) (Council et al., 2000) can enhance tumor progression but not of forming new tumors and decreasing the intake of this metal stops the development of the disease, indicating that copper is not capable of producing transformation but is a necessary nutrient for these cells. That is why copper has been described as a stimulator of tumor development and not an initiator of transformation, as it promotes several processes related to cancer (Ishida et al., 2013).

Several types of cancer cells possess very high levels of the transmembrane transporter CTR1, explaining how these cells obtain the high concentrations of copper. Cancer cells treated with copper chelator treatments have dramatically decreased ATP production even when there is an increase in glycolysis, indicating that these cells still rely on OXPHOS. Thus, these elevated levels of copper can regulate the production of ATP by OXPHOS to meet the demands of the accelerated proliferation found in solid cancers, indicating that copper may be a limiting nutrient for tumor development (Ishida et al., 2013). The high copper content could be activating the function as a transcription factor of ATOX1, further enhancing cell proliferation (Itoh et al., 2008).

ATOX1 is established to perform a vital function in copper homeostasis (Hatori and Lutsenko 2016). Moreover, ATOX1 shows high expression in different cancers (Cai and Peng 2013; Blockhuys et al., 2017) and has been described to present a critical function in angiogenesis (Chen et al., 2015). Remarkably, ATOX1 is a copper-dependent transcription factor (requires copper binding) that stimulates the expression of NADPH oxidase p47phox and Cyclin D1, relating to increased ROS generation and proliferation, respectively (Hamza et al., 2001; Itoh et al., 2008; Chen et al., 2015). The nuclear localization of ATOX1 is associated with the severity of metastatic colorectal cancer. Stimulation of colon cancer metastasis with activin A promotes ATOX1 nuclear translocation in metastatic SW620 and nonmetastatic SW480 colon cancer cell lines. Knockdown of ATOX1 in SW620 decreased ROS generation and colony formation through a decreased expression of NADPH oxidase p47phox and Cyclin D1 (Jana et al., 2020). Individual cell migration is an early step in breast cancer metastasis; thus, ATOX1 silencing decreases the breast cancer cell migration velocity via coordinated copper transport in the ATP7A-LOX (proenzyme of lysyl oxidase) axis (Blockhuys et al., 2020).

Considering possible copper effects on tumor development, the gene TP53-which encodes for the tumor suppressor protein p53-should be mentioned, as it is the most frequently mutated

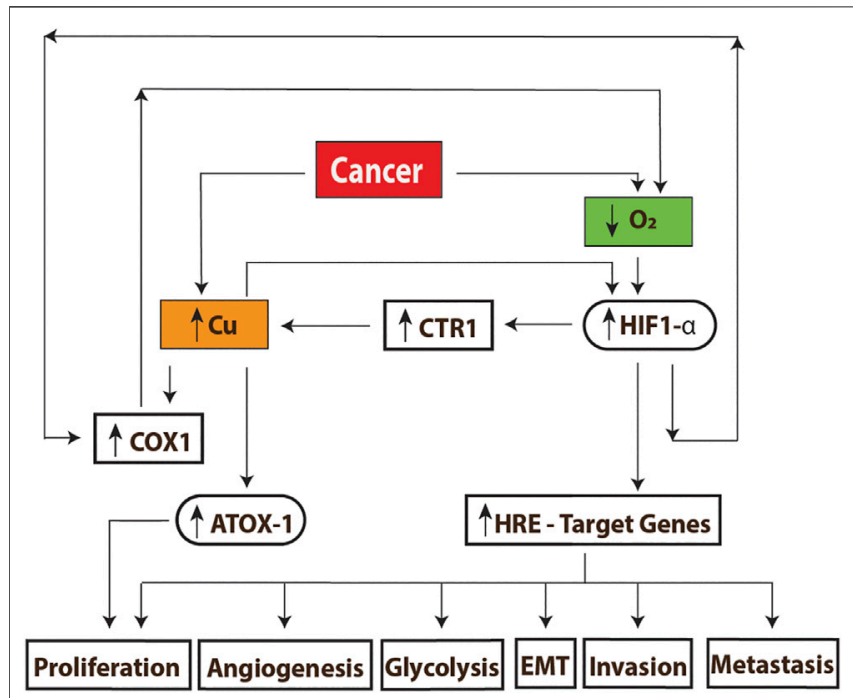

FIGURE 5|Mechanisms of copper action in cancer. (A) The high energy demand found in these cells decreases the oxygen concentrations, producing hypoxia; this causes an increase in the transmembrane transporter CTR1, which causes an increase of the intracellular concentrations of copper. The levels of this metal together with the reduced concentration of oxygen can stabilize and activate the HIF-1 transcription factor, triggering the activation of genes related to growth and tumor development. On the other hand, the high copper content promotes the assembly of complex IV (COX1) which is followed by the upregulation of OXPHOS. A higher oxygen demand will induce the upregulation of HIF1-alpha, creating a virtuous cycle for tumor growth. Excess of copper will also up regulate ATOX1 expression to promote cell proliferation as well. HRE: hypoxia-response Element. EMT:

epithelial-mesenchymal Transition.

protein in human cancers (Kastenhuber and Lowe 2017). The protein p53 is a transcription factor that possesses a single zinc ion near its DNA-binding interface, and deficient zinc through competition with copper causes p53 to misfold, which results in functional loss of transcriptional activity (Loh 2010; Formigari et al., 2013).

Other mechanistic insight about copper action in cancer would be the oncogenic BRAFV600E that phosphorylates and activates the MEK1 and MEK2 kinases, which in turn phosphorylates and activates ERK1 and ERK2 kinases, stimulating the MAPK (mitogen-activated protein kinase) pathway to promote cancer. Alterations of the MEK1 interaction with copper and decrease of copper influx shooting down CTR1 decrease BRAFV600E driven signaling and tumorigenesis (Brady et al., 2014).

Moreover, the autophagy signaling is implicated in cellular proliferation, and copper is necessary for the activity of the ULK1 and ULK2 (ULK1/2) autophagic kinases, by directly binding $\mathrm{Cu}$ to $\mathrm{ULK} 1 / 2$. Elevated intracellular copper levels are related to starvation-induced autophagy and are enough to upregulate the ULK1 kinase activity and autophagic flux (Tsang et al., 2020). Copper-treated K562 cells showed reduced levels of protein P62, indicating an increased autophagic flux and mitochondrial fusion, which is restored to basal levels by TBAP (antioxidant molecule that mimics SOD2) treatment, suggesting that copper-induced ROS speeds up mitochondrial 
turnover (Ruiz et al., 2016). The loss of the copper transporter CTR1 decreased the growth and survival of KRASG12D-driven lung tumors, which are reliant on Cu-ULK1 binding and are coupled to reduced autophagy and signaling. This work established the molecular basis of copper chelation to prevent autophagy signaling, copper-dependent ROS generation (Fenton reaction), and glycolytic metabolism from limiting proliferation and improving cancer patients' survival (Tsang et al., 2020).

Interestingly, copper also has a role in regulating the programmed death ligand 1 (PD-L1), which is overexpressed by cancer cells to protect themselves from antitumor immune responses. Copper supplementation in cancer cells enhanced PDL1 expression, driving cancer immune evasion, while copper chelation promoted ubiquitin-mediated degradation of PD-L1 and increased the number of tumor-infiltrating CD8+T and natural-killer cells (Voli et al., 2020).

The presence of significant high serum copper levels in nonalcoholic fatty liver disease (NAFLD) in cirrhotic patients increased cell growth, migration, and invasion of liver cancer cells through the modulation of the MYC/CTR1 axis (MYC protooncogene, bHLH transcription factor/copper transport protein) (Porcu et al., 2018). Figure 5 summarizes the main findings of copper action in cancer.

\section{FINAL THOUGHTS}

As largely discussed in this review, cellular copper concentration has a direct impact on cell proliferation, differentiation, or cell death. Copper property to control cell fate has been exploited by modern medicine in the field of stem cell-based regenerative medicine as well as in the fight against cancer. The main action of copper is at the level of mitochondrial function and metabolism because copper is a prosthetic group of respiratory complex IV. Copper bioavailability has been shown to regulate both expression and activity of complex IV and then the balance between glycolysis and OXPHOS. Copper deficiency will favor glycolysis and cell proliferation, and a noncytotoxic copper overload, OXPHOS, and cell differentiation. However, the final outcome will be tissue- or cell-specific. Changes in mitochondrial metabolism also impact the amount intermediate metabolites, such as acetyl-CoA, citrate, a-ketoglutarate, ROS, and NAD+/NADH among others, which have a direct effect on the transcriptional and epigenetic regulation of cells, by means of mitochondria-nucleus retrograde communication. Copper-induced transcriptional regulation also occurs via ATOX1, a copper-dependent transcription factor associated with angiogenesis and tumor development. On the other hand, an excessive copper overload will induce a massive amount of ROS, due to Fenton and Haber-Weiss reactions, causing cell death via apoptosis or necrosis. Thus, copper action involves either going from mitochondrial-induced metabolic reprogramming to genetic reprogramming to change cellular phenotype, or cell death.

Pharmacological modulation of intracellular copper concentrations is effective to control stem cell expansion and/ or differentiation for regenerative medicine as well as to control tumor growth and cancer development. Cancer cells have been shown to accumulate more copper than healthy cells and to be sensitive to proteasome inhibition. Therefore, many copperbased pharmacological strategies have been developed to eliminate cancer cells. Those include copper chelators, copperdepleting nanoparticles, and copper-based compounds which have been shown to be successful both in vitro and in vivo. Nevertheless, more basic and clinical research is still needed regarding cell-specific targeting and delivery of those copper compounds.

The study of copper on mitochondrial function and metabolism has opened a powerful and novel route for drug discovery and nanobiotechnology, not only for treating catastrophic diseases like cancer but also for protecting and/or improving mitochondrial activity and capacity. Remarkably, proper mitochondrial function is associated with healthy aging and the delay of aging-associated diseases.

\section{AUTHOR CONTRIBUTIONS}

LR and AL wrote, discussed, and reviewed the manuscript. Furthermore, LR and AL designed and created figures and tables. AE conceived, funded, wrote, discussed, and reviewed the manuscript.

\section{FUNDING}

Funding for this study was provided by the National Agency of Investigation and Development (ANID), Chile by means of its FONDECYT program, and also, by the Millenium Institute on Immunology and Immunotherapy.

\section{ACKNOWLEDGMENTS}

This study was supported by the grants FONDECYT 1180983 (AE) and Millennium Institute of Immunology and Immunotherapy P09-016-F (AE).

\section{SUPPLEMENTARY MATERIAL}

The Supplementary Material for this article can be found online at: https://www.frontiersin.org/articles/10.3389/fmolb.2021.711227/ full\#supplementary-material 


\section{REFERENCES}

Acín-Pérez, R., Fernández-Silva, P., Peleato, M. L., Pérez-Martos, A., and Enriquez, J. A. (2008). Respiratory Active Mitochondrial Supercomplexes. Mol. Cel 32, 529-53910. doi:10.1016/j.molcel.2008.10.021

Anderson, A. J., Jackson, T. D., Stroud, D. A., and Stojanovski, D. (2019). Mitochondria-hubs for Regulating Cellular Biochemistry: Emerging Concepts and Networks. Open Biol. 9, 190126. doi:10.1098/rsob.190126

Arnal, N., de Alaniz, M. J. T., and Marra, C. A. (2012). Cytotoxic Effects of Copper Overload on suman-Derived Lung and Liver Cells in Culture. Biochim. Biophys. Acta (Bba) - Gen. Subjects 1820, 931-93910. doi:10.1016/ j.bbagen.2012.03.007

Aston, N. S., Watt, N., Morton, I. E., Tanner, M. S., and Evans, G. S. (2000). Copper Toxicity Affects Proliferation and Viability of Human Hepatoma Cells (HepG2 Line). Hum. Exp. Toxicol. 19, 367-37610. doi:10.1191/096032700678815963

Bae, B., and Percival, S. S. (1993). Retinoic Acid-Induced HL-60 Cell Differentiation Is Augmented by Copper Supplementation. J. Nutr. 123, 997-1002. doi:10.1093/jn/123.6.997

Baker, Z. N., Cobine, P. A., and Leary, S. C. (2017). The Mitochondrion: a central Architect of Copper Homeostasis. Metallomics 9, 1501-151210. doi:10.1039/ c7mt00221a

Barrett, S., De Franco, M., Kellett, A., Dempsey, E., and Marzano, C. (2020). Anticancer Activity, DNA Binding and Cell Mechanistic Studies of EstrogenFunctionalised $\mathrm{Cu}(\mathrm{II})$ Complexes. JBIC J. Biol. Inorg. Chem. 25, 49-60. doi:10.1007/s00775-019-01732-8

Bigarella, C. L., Liang, R., and Ghaffari, S. (2014). Stem Cells and the Impact of ROS Signaling, Cambridge, England. Development 141, 4206-4218. doi:10.1242/ dev.107086

Björkblom, B., Adilbayeva, A., Maple-Grødem, J., Piston, D., Ökvist, M., Xu, X. M., et al. (2013). Parkinson Disease Protein DJ-1 Binds Metals and Protects against Metal-Induced Cytotoxicity. J. Biol. Chem. 288, 22809-22820. doi:10.1074/ jbc.m113.482091

Blockhuys, S., Celauro, E., Hildesjö, C., Feizi, A., Stål, O., Fierro-González, J. C., et al. (2017). Defining the Human Copper Proteome and Analysis of its Expression Variation in Cancers. Metallomics 9, 112-123. doi:10.1039/ c6mt00202a

Blockhuys, S., Zhang, X., and Wittung-Stafshede, P. (2020). Single-cell Tracking Demonstrates Copper Chaperone Atox 1 to Be Required for Breast Cancer Cell Migration. Proc. Natl. Acad. Sci. 117, 2014. doi:10.1073/pnas.1910722117

Bode, A. M., Miller, L. A., Faber, J., and Saari, J. T. (1992). Mitochondrial Respiration in Heart, Liver, and Kidney of Copper-Deficient Rats. J. Nutr. Biochem. 3, 668-672. doi:10.1016/0955-2863(92)90088-z

Boekema, E. J., and Braun, H-P. (2007). Supramolecular Structure of the Mitochondrial Oxidative Phosphorylation System. J. Biol. Chem. 282, 1-4. doi:10.1074/jbc.r600031200

Bolamperti, L., Leone, M. A., Stecco, A., Reggiani, M., Pirisi, M., Carriero, A., et al. (2009). Myeloneuropathy Due to Copper Deficiency: Clinical and MRI Findings after Copper Supplementation. Neurol. Sci. 30, 521-524. doi:10.1007/s10072-009-0126-7

Bonnet, S., Archer, S. L., Allalunis-Turner, J., Haromy, A., Beaulieu, C., Thompson, R., et al. (2007). A Mitochondria-K+ Channel Axis Is Suppressed in Cancer and its Normalization Promotes Apoptosis and Inhibits Cancer Growth. Cancer Cell 11, 37-51. doi:10.1016/j.ccr.2006.10.020

Boulet, A., Vest, K. E., Maynard, M. K., Gammon, M. G., Russell, A. C., Mathews, A. T., et al. (2018). The Mammalian Phosphate Carrier SLC25A3 Is a Mitochondrial Copper Transporter Required for Cytochrome C Oxidase Biogenesis. J. Biol. Chem. 293, 1887-1896. doi:10.1074/jbc.ra117.000265

Brady, D. C., Crowe, M. S., Turski, M. L., Hobbs, G. A., Yao, X., Chaikuad, A., et al. (2014). Copper Is Required for Oncogenic BRAF Signalling and Tumorigenesis. Nature 509, 492-496. doi:10.1038/nature13180

Brem, S., Grossman, S. A., Carson, K. A., New, P., Phuphanich, S., Alavi, J. B., et al. (2005). Phase 2 Trial of Copper Depletion and Penicillamine as Antiangiogenesis Therapy of Glioblastoma. Neuro-Oncology 7, 246-253. doi:10.1215/s1152851704000869

Brem, S. (1999). Angiogenesis and Cancer Control: From Concept to Therapeutic Trial. Cancer Control 6, 1-18. doi:10.1177/107327489900600502
Brem, S. S., Zagzag, D., Tsanaclis, A. M., Gately, S., Elkouby, M. P., and Brien, S. E. (1990). Inhibition of Angiogenesis and Tumor Growth in the Brain. Suppression of Endothelial Cell Turnover by Penicillamine and the Depletion of Copper, an Angiogenic Cofactor. Am. J. Pathol. 137, 1121-1142.

Brewer, G. J. (2001). Copper Control as an Antiangiogenic Anticancer Therapy: Lessons from Treating Wilson's Disease. Exp. Biol. Med. 226, 665-673. doi:10.1177/153537020222600712

Brewer, G. J. (2003). Copper in Medicine. Curr. Opin. Chem. Biol. 7, 207-212. doi:10.1016/s1367-5931(03)00018-8

Brewer, G. J., Dick, R. D., Grover, D. K., LeClaire, V., Tseng, M., Wicha, M., et al. (2000). Treatment of Metastatic Cancer with Tetrathiomolybdate, an Anticopper, Antiangiogenic Agent: Phase I Study. Clin. Cancer Res. 6, 1-10.

Brewer, G. J., Hedera, P., Kluin, K. J., Carlson, M., Askari, F., Dick, R. B., et al. (2003). Treatment of wilson Disease with Ammonium Tetrathiomolybdate: Iii. Initial Therapy in a Total of 55 Neurologically Affected Patients and Follow-Up with Zinc Therapy. Arch. Neurol. 60, 379-385. doi:10.1001/archneur.60.3.379

Brustolin, L., Nardon, C., Pettenuzzo, N., Zuin Fantoni, N., Quarta, S., Chiara, F., et al. (2018). Synthesis, Chemical Characterization and Cancer Cell GrowthInhibitory Activities of $\mathrm{Cu}(\mathrm{ii})$ and $\mathrm{Ru}$ (iii) Aliphatic and Aromatic Dithiocarbamato Complexes. Dalton Trans. 47, 15477-15486. doi:10.1039/ c8dt02965b

Brustolin, L., Pettenuzzo, N., Nardon, C., Quarta, S., Montagner, I., Pontisso, P., et al. (2020). Labelled Micelles for the Delivery of Cytotoxic $\mathrm{Cu}(\mathrm{II})$ and $\mathrm{Ru}(\mathrm{III})$ Compounds in the Treatment of Aggressive Orphan Cancers: Design and Biological In Vitro Data. J. Inorg. Biochem. 213, 111259. doi:10.1016/ j.jinorgbio.2020.111259

Bustos, R. I., Jensen, E. L., Ruiz, L. M., Rivera, S., Ruiz, S., Ruiz, S., et al. (2013). Copper Deficiency Alters Cell Bioenergetics and Induces Mitochondrial Fusion through Up-Regulation of MFN2 and OPA1 in Erythropoietic Cells. Biochem. Biophys. Res. Commun. 437, 426-432. doi:10.1016/j.bbrc.2013.06.095

Cai, H., and Peng, F. (2013). Knockdown of Copper Chaperone Antioxidant-1 by RNA Interference Inhibits Copper-Stimulated Proliferation of Non-small Cell Lung Carcinoma Cells. Oncol. Rep. 30, 269-275. doi:10.3892/or.2013.2436

Cerone, S. I., Sansinanea, A. S., Streitenberger, S. A., Garcia, M. C., and Auza, N. J. (2000). Cytochrome C Oxidase, $\mathrm{Cu}, \mathrm{Zn}$-Superoxide Dismutase, and Ceruloplasmin Activities in Copper-Deficient Bovines. Biol. Trace Elem. Res. 73, 269-278. doi:10.1385/bter:73:3:269

Chang, C-R., and Blackstone, C. (2010). Dynamic Regulation of Mitochondrial Fission through Modification of the Dynamin-Related Protein Drp1 in Mitochondrial Research In Translational Medicine. Editors Y. H. Wei, C. R. Tzeng, and H. M. Lee, 34-39. doi:10.1111/j.1749-6632.2010.05629.x

Chen, G-F., Sudhahar, V., Youn, S-W., Das, A., Cho, J., Kamiya, T., et al. (2015). Copper Transport Protein Antioxidant-1 Promotes Inflammatory Neovascularization via Chaperone and Transcription Factor Function. Scientific Rep. 5, 14780. doi:10.1038/srep14780

Chen, X., Jennings, D. B., and Medeiros, D. M. (2002). Impaired Cardiac Mitochondrial Membrane Potential and Respiration in Copper-Deficient Rats. J. Bioenerg. Biomembr 34, 397-406. doi:10.1023/a:1021258204921

Chen, X., Medeiros, D. M., and Jennings, D. (2005). Mitochondrial Membrane Potential Is Reduced in Copper-Deficient C2C12 Cells in the Absence of Apoptosis. Biol. Trace Elem. Res. 106, 51-63. doi:10.1385/BTER:106:1:051

Chung, J., Chen, C., and Paw, B. H. (2012). Heme Metabolism and Erythropoiesis. Curr. Opin. Hematol. 19, 156-162. doi:10.1097/moh.0b013e328351c48b

Cobine, P. A., Moore, S. A., and Leary, S. C. (2021). Getting Out what You Put in: Copper in Mitochondria and its Impacts on Human Disease. Biochim. Biophys. Acta (Bba) - Mol. Cel Res. 1868, 118867. doi:10.1016/j.bbamcr.2020.118867

Cobine, P. A., Ojeda, L. D., Rigby, K. M., and Winge, D. R. (2004). Yeast Contain a Non-proteinaceous Pool of Copper in the Mitochondrial Matrix. J. Biol. Chem. 279, 14447-14455. doi:10.1074/jbc.m312693200

Cobine, P. A., Pierrel, F., Bestwick, M. L., and Winge, D. R. (2006a). Mitochondrial Matrix Copper Complex Used in Metallation of Cytochrome Oxidase and Superoxide Dismutase. J. Biol. Chem. 281, 36552-36559. doi:10.1074/ jbc.m606839200

Cobine, P. A., Pierrel, F., and Winge, D. R. (2006b). Copper Trafficking to the Mitochondrion and Assembly of Copper Metalloenzymes. Biochim. Biophys. Acta (Bba) - Mol. Cel Res. 1763, 759-772. doi:10.1016/j.bbamcr.2006.03.002

Council, N. R., Sciences, C. L., Toxicology, B. E. S., and Water, C. C. D. (2000). Copper in Drinking Water. Washington, DC: National Academies Press. 
Crowe, A., Jackaman, C., Beddoes, K. M., Ricciardo, B., and Nelson, D. J. (2013). Rapid Copper Acquisition by Developing Murine Mesothelioma: Decreasing Bioavailable Copper Slows Tumor Growth, Normalizes Vessels and Promotes T Cell Infiltration. Plos One 8, e73684. doi:10.1371/journal.pone.0073684

Cui, L., Gouw, A. M., LaGory, E. L., Guo, S., Attarwala, N., Tang, Y., et al. (2021). Mitochondrial Copper Depletion Suppresses Triple-Negative Breast Cancer in Mice. Nat. Biotechnol. 39 (3), 357-367. doi:10.1038/s41587-020-0707-9

Dahlberg, A., Delaney, C., and Bernstein, I. D. (2011). Ex Vivo expansion of Human Hematopoietic Stem and Progenitor Cells. Blood 117, 6083-6090. doi:10.1182/ blood-2011-01-283606

Dallman, P. R., and Goodman, J. R. (1970). Enlargement of Mitochondrial Compartment in Iron and Copper Deficiency. Blood 35, 496-505. doi:10.1182/blood.v35.4.496.496

Daniel, K. G., Gupta, P., Harbach, R. H., Guida, W. C., and Dou, Q. P. (2004). Organic Copper Complexes as a New Class of Proteasome Inhibitors and Apoptosis Inducers in Human Cancer Cells. Biochem. Pharmacol. 67, 1139-1151. doi:10.1016/j.bcp.2003.10.031

Desler, C., Hansen, T. L., Frederiksen, J. B., Marcker, M. L., Singh, K. K., and Juel Rasmussen, L. (2012). Is There a Link between Mitochondrial Reserve Respiratory Capacity and Aging? J. Aging Res. 2012, 192503-03. doi:10.1155/2012/192503

Diaz, F., Fukui, H., Garcia, S., and Moraes, C. T. (2006). Cytochrome C Oxidase Is Required for the Assembly/Stability of Respiratory Complex I in Mouse Fibroblasts. Mol. Cell Biol. 26, 4872-4881. doi:10.1128/mcb.01767-05

Dudkina, N. V., Sunderhaus, S., Boekema, E. J., and Braun, H. P. (2008). The Higher Level of Organization of the Oxidative Phosphorylation System: Mitochondrial Supercomplexes. J. Bioenerg. biomembranes 40, 419-424. doi:10.1007/s10863-008-9167-5

Fibach, E., and Rachmilewitz, E. (2008). The Role of Oxidative Stress in Hemolytic Anemia. Curr. Mol. Med. 8, 609-619. doi:10.2174/ 156652408786241384

Fischer, A. C., and Goode, C. A. (1994). Interaction of Bovine Ceruloplasmin with Erythrocytes. Prep. Biochem. 24, 151-165. doi:10.1080/10826069408010089

Folkman, J., and Klagsbrun, M. (1987). Angiogenic Factors. Science 235, 442-447. doi:10.1126/science. 2432664

Folmes, C. D. L., Dzeja, P. P., Nelson, T. J., and Terzic, A. (2012). Mitochondria in Control of Cell Fate. Circ. Res. 110, 526-529. doi:10.1161/res.0b013e31824ae5c1

Fong, T., Vij, R., Vijayan, A., DiPersio, J., and Blinder, M. (2007). Copper Deficiency: an Important Consideration in the Differential Diagnosis of Myelodysplastic Syndrome. Haematologica 92, 1429-1430. doi:10.3324/ haematol.11314

Fontenay, M., Cathelin, S., Amiot, M., Gyan, E., and Solary, E. (2006). Mitochondria in Hematopoiesis and Hematological Diseases. Oncogene 25, 4757-4767. doi:10.1038/sj.onc. 1209606

Formigari, A., Gregianin, E., and Irato, P. (2013). The Effect of Zinc and the Role of P53 in Copper-Induced Cellular Stress Responses. J. Appl. Toxicol. 33, 527-536. doi:10.1002/jat.2854

Fukai, T., and Ushio-Fukai, M. (2011). Superoxide Dismutases: Role in Redox Signaling, Vascular Function, and Diseases. Antioxid. Redox Signaling 15, 1583-1606. doi:10.1089/ars.2011.3999

Gabreyes, A. A., Abbasi, H. N., Forbes, K. P., McQuaker, G., Duncan, A., and Morrison, I. (2013). Hypocupremia Associated Cytopenia and Myelopathy: a National Retrospective Review. Eur. J. Haematol. 90, 1-9. doi:10.1111/ ejh. 12020

Gallagher, C. H., Reeve, V. E., and Wright, R. (1973). Copper Deficiency in the Rat. Effect on the Ultrastructure of Hepatocytes. Aust. J. Exp. Biol. Med. Sci. 51, 181-189. doi:10.1038/icb.1973.15

Gérard, C., Bordeleau, L-J., Barralet, J., and Doillon, C. J. (2010). The Stimulation of Angiogenesis and Collagen Deposition by Copper. Biomaterials 31, 824-831. doi:10.1016/j.biomaterials.2009.10.009

Getz, J., Lin, D., and Medeiros, D. M. (2011). The Cardiac Copper Chaperone Proteins Scol and CCS Are Up-Regulated, but Cox 1 and Cox4 Are DownRegulated, by Copper Deficiency. Biol. Trace Elem. Res. 143, 368-377. doi:10.1007/s12011-010-8858-Z

Ghosh, A., Trivedi, P. P., Timbalia, S. A., Griffin, A. T., Rahn, J. J., Chan, S. S., et al. (2014). Copper Supplementation Restores Cytochrome C Oxidase Assembly
Defect in a Mitochondrial Disease Model of COA6 Deficiency. Hum. Mol. Genet. 23, 3596-3606. doi:10.1093/hmg/ddu069

Gletsu-Miller, N., Broderius, M., Frediani, J. K., Zhao, V. M., Griffith, D. P., Sweeney, J. F., et al. (2011). Incidence and Prevalence of Copper Deficiency Following Roux-En-Y Gastric Bypass Surgery. Int. J. Obes. 36, 328. doi:10.1038/ ijo.2011.159

Gonzalez-Ibanez, A. M., Ruiz, L. M., Jensen, E., Echeverria, C. A., Romero, V., Stiles, L., et al. (2020). Erythroid Differentiation and Heme Biosynthesis Are Dependent on a Shift in the Balance of Mitochondrial Fusion and Fission Dynamics. Front Cel Dev Biol 8, 592035-35. doi:10.3389/fcell.2020.592035

Goodman, J. R., Warshaw, J. B., and Dallman, P. R. (1970). Cardiac Hypertrophy in Rats with Iron and Copper Deficiency: Quantitative Contribution of Mitochondrial Enlargement. Pediatr. Res. 4, 244-256. doi:10.1203/00006450197005000-00003

Goodman, V. L., Brewer, G. J., and Merajver, S. D. (2004). Copper Deficiency as an Anti-cancer Strategy. Endocrine-Related Cancer 11, 255-263. doi:10.1677/ erc. 0.0110255

Goyens, P., Brasseur, D., and Cadranel, S. (1985). Copper Deficiency in Infants with Active Celiac Disease. J. Pediatr. Gastroenterol. Nutr. 4, 677-680. doi:10.1097/00005176-198508000-00033

Gregg, X. T., Reddy, V., and Prchal, J. T. (2002). Copper Deficiency Masquerading as Myelodysplastic Syndrome. Blood 100, 1493-1495. doi:10.1182/blood-200201-0256

Gregory, C., and Eaves, A. (1978). Three Stages of Erythropoietic Progenitor Cell Differentiation Distinguished by a Number of Physical and Biologic Properties. Blood 51, 527-537. doi:10.1182/blood.v51.3.527.bloodjournal513527

Griffith, D. P., Liff, D., Ziegler, T. R., Esper, G. J., and Winton, E. F. (2009). Acquired Copper Deficiency: A Potentially Serious and Preventable Complication Following Gastric Bypass Surgery. Obes. (Silver Spring Md) 17, 827-831. doi:10.1038/oby.2008.614

Gudekar, N., Shanbhag, V., Wang, Y., Ralle, M., Weisman, G. A., and Petris, M. J. (2020). Metallothioneins Regulate ATP7A Trafficking and Control Cell Viability during Copper Deficiency and Excess. Scientific Rep. 10, 7856. doi:10.1038/s41598-020-64521-3

Gullino, P. M. (1986). Considerations on the Mechanism of the Angiogenic Response. Anticancer Res. 6, 153-158.

Gupta, A., Bhattacharjee, A., Dmitriev, O. Y., Nokhrin, S., Braiterman, L., Hubbard, A. L., et al. (2011). Cellular Copper Levels Determine the Phenotype of the Arg875 Variant of ATP7B/Wilson Disease Protein. Proc. Natl. Acad. Sci. U S A. 108, 5390-5395. doi:10.1073/pnas.1014959108

Gupte, A., and Mumper, R. J. (2009). Elevated Copper and Oxidative Stress in Cancer Cells as a Target for Cancer Treatment. Cancer Treat. Rev. 35, 32-46. doi:10.1016/j.ctrv.2008.07.004

Halfdanarson, T. R., Kumar, N., Li, C-Y., Phyliky, R. L., and Hogan, W. J. (2008). Hematological Manifestations of Copper Deficiency: a Retrospective Review. Eur. J. Haematol. 80, 523-531. doi:10.1111/j.1600-0609.2008.01050.x

Hamza, I., Faisst, A., Prohaska, J., Chen, J., Gruss, P., and Gitlin, J. D. (2001). The Metallochaperone Atox1 Plays a Critical Role in Perinatal Copper Homeostasis. Proc. Natl. Acad. Sci. United States America 98, 6848-6852. doi:10.1073/ pnas. 111058498

Hanahan, D., and Weinberg Robert, A. (2011). Hallmarks of Cancer: The Next Generation. Cell 144, 646-674. doi:10.1016/j.cell.2011.02.013

Hatori, Y., and Lutsenko, S. (2016). The Role of Copper Chaperone Atoxl in Coupling Redox Homeostasis to Intracellular Copper Distribution. Antioxidants 5, 25. doi:10.3390/antiox5030025

Hirase, N., Abe, Y., Sadamura, S., Yufu, Y., Muta, K., Umemura, T., et al. (1992). Anemia and Neutropenia in a Case of Copper Deficiency: Role of Copper in Normal Hematopoiesis. Acta Haematologica 87, 195-197. doi:10.1159/ 000204758

Hlynialuk Christopher, J., Ling, B., Baker Zakery, N., Cobine Paul, A., Yu Lisa, D., Boulet, A., et al. (2015). The Mitochondrial Metallochaperone SCO1 Is Required to Sustain Expression of the High-Affinity Copper Transporter CTR1 and Preserve Copper Homeostasis. Cel Rep. 10, 933-943. doi:10.1016/ j.celrep.2015.01.019

Horn, D., and Barrientos, A. (2008). Mitochondrial Copper Metabolism and Delivery to Cytochrome C Oxidase. Iubmb Life 60, 421-429. doi:10.1002/ iub. 50 
Hu, G. (1998). Copper Stimulates Proliferation of Human Endothelial Cells under Culture. J. Biol. Chem. 69, 326-335. doi:10.1002/(sici)1097-4644(19980601)69: $3<326::$ aid-jcb10>3.0.co;2-a

Hu, H-L., Ni, X-S., Duff-Canning, S., and Wang, X-P. (2016). Oxidative Damage of Copper Chloride Overload to the Cultured Rat Astrocytes. Am. J. Translational Res. 8, 1273-1280.

Hu, X., Go, Y-M., and Jones, D. P. (2020). Omics Integration for Mitochondria Systems Biology. Antioxid. Redox Signaling 32, 853-872. doi:10.1089/ ars.2019.8006

Huang, X., Pierce, L. J., Cobine, P. A., Winge, D. R., and Spangrude, G. J. (2009). Copper Modulates the Differentiation of Mouse Hematopoietic Progenitor Cells in Culture. Cel Transplant. 18, 887-897. doi:10.3727/096368909x471152

Huang, Z. L., and Failla, M. L. (2000). Copper Deficiency Suppresses Effector Activities of Differentiated U937 Cells. J. Nutr. 130, 1536-1542. doi:10.1093/jn/ 130.6.1536

Huttemann, M., Lee, I., Samavati, L., Yu, H., and Doan, J. W. (2007). Regulation of Mitochondrial Oxidative Phosphorylation through Cell Signaling. Biochim. Biophys. Acta 1773, 1701-1720. doi:10.1016/j.bbamcr.2007.10.001

Inesi, G. (2016). Molecular Features of Copper Binding Proteins Involved in Copper Homeostasis. Iubmb Life 69 (4), 211-217. doi:10.1002/iub.1590

Ishida, S., Andreux, P., Poitry-Yamate, C., Auwerx, J., and Hanahan, D. (2013). Bioavailable Copper Modulates Oxidative Phosphorylation and Growth of Tumors. Proc. Natl. Acad. Sci. United States America 110, 19507-19512. doi:10.1073/pnas.1318431110

Itoh, S., Kim, H., Nakagawa, O., Ozumi, K., Lessner, S., Aoki, H., et al. (2008). Novel Role of Antioxidant-1 (Atox1) as a Copper-dependent Transcription Factor Involved in Cell Proliferation. J. Biol. Chem. 283, 9157-9167. doi:10.1074/ jbc.m709463200

Jaiser, S. R., and Winston, G. P. (2010). Copper Deficiency Myelopathy. J. Neurol. 257, 869-881. doi:10.1007/s00415-010-5511-x

Jana, A., Das, A., Krett, N. L., Guzman, G., Thomas, A., Mancinelli, G., et al. (2020). Nuclear Translocation of Atoxl Potentiates Activin A-Induced Cell Migration and colony Formation in colon Cancer. Plos One 15, e0227916. doi:10.1371/ journal.pone.0227916

Jensen, E. L., Gonzalez-Ibanez, A. M., Mendoza, P., Ruiz, L. M., Riedel, C. A., Simon, F., et al. (2019). Copper Deficiency-Induced Anemia Is Caused by a Mitochondrial Metabolic Reprograming in Erythropoietic Cells. Metallomics 11, 282-290. doi:10.1039/c8mt00224j

Jett, K. A., and Leary, S. C. (2018). Building the Cu A Site of Cytochrome C Oxidase: A Complicated, Redox-dependent Process Driven by a Surprisingly Large Complement of Accessory Proteins. J. Biol. Chem. 293, 4644-4652. doi:10.1074/jbc.r117.816132

Jia, X., Chen, L., Li, J., Su, R., Shi, D., and Tang, Z. (2012). Effect of Copper Chloride Exposure on the Membrane Potential and Cytosolic Free Calcium in Primary Cultured Chicken Hepatocytes. Biol. Trace Elem. Res. 148, 331-335. doi:10.1007/s12011-012-9376-y

Johnson, P. E., Milne, D. B., and Lykken, G. I. (1992). Effects of Age and Sex on Copper Absorption, Biological Half-Life, and Status in Humans. Am. J. Clin. Nutr. 56, 917-925. doi:10.1093/ajcn/56.5.917

Kadenbach, B., and Hüttemann, M. (2015). The Subunit Composition and Function of Mammalian Cytochrome C Oxidase. Mitochondrion 24, 64-76. doi:10.1016/j.mito.2015.07.002

Kastenhuber, E. R., and Lowe, S. W. (2017). Putting P53 in Context. Cell 170, 1062-1078. doi:10.1016/j.cell.2017.08.028

Kim, B-E., Nevitt, T., and Thiele, D. J. (2008). Mechanisms for Copper Acquisition, Distribution and Regulation. Nat. Chem. Biol. 4, 176-185. doi:10.1038/ nchembio.72

Kim, B-E., Turski, M. L., Nose, Y., Casad, M., Rockman, H. A., and Thiele, D. J. (2010). Cardiac Copper Deficiency Activates a Systemic Signaling Mechanism that Communicates with the Copper Acquisition and Storage Organs. Cel Metab. 11, 353-363. doi:10.1016/j.cmet.2010.04.003

Klöppel, C., Suzuki, Y., Kojer, K., Petrungaro, C., Longen, S., Fiedler, S., et al. (2011). Mia40-dependent Oxidation of Cysteines in Domain I of Ccs1 Controls its Distribution between Mitochondria and the Cytosol. Mol. Biol. Cel 22, 3749-3757. doi:10.1091/mbc.e11-04-0293

Koch, J. R., and Schmid, F. X. (2014). Mia40 Combines Thiol Oxidase and Disulfide Isomerase Activity to Efficiently Catalyze Oxidative Folding in Mitochondria. J. Mol. Biol. 426, 4087-4098. doi:10.1016/j.jmb.2014.10.022
Kochi, N., Tani, E., Morimura, T., and Itagaki, T. (1983). Immunohistochemical Study of Fibronectin in Human Glioma and Meningioma. Acta Neuropathologica 59, 119-126. doi:10.1007/bf00691597

Koopman, W. J. H., Willems, P. H. G. M., and Smeitink, J. A. M. (2012). Monogenic Mitochondrial Disorders. New Engl. J. Med. 366, 1132-1141. doi:10.1056/ nejmra1012478

Kopp, S. J., Klevay, L. M., and Feliksik, J. M. (1983). Physiological and Metabolic Characterization of a Cardiomyopathy Induced by Chronic Copper Deficiency. Am. J. Physiol. - Heart Circulatory Physiol. 245, H855-H66. doi:10.1152/ ajpheart.1983.245.5.h855

Lamb, A. L., Torres, A. S., O'Halloran, T. V., and Rosenzweig, A. C. (2000), Heterodimer Formation between Superoxide Dismutase and its Copper Chaperone. Biochemistry 39, 14720-14727. doi:10.1021/bi002207a

Larin, D., Mekios, C., Das, K., Ross, B., Yang, A-S., and Gilliam, T. C. (1999). Characterization of the Interaction between the Wilson and Menkes Disease Proteins and the Cytoplasmic Copper Chaperone. Hahlp. J. Biol. Chem. 274, 28497-28504. doi:10.1074/jbc.274.40.28497

Lassi, K. C., and Prohaska, J. R. (2012). Erythrocyte Copper Chaperone for Superoxide Dismutase Is Increased Following Marginal Copper Deficiency in Adult and Postweanling Mice. J. Nutr. 142, 292-297. doi:10.3945/ jn.111.150755

Leary, S. C., Sasarman, F., Nishimura, T., and Shoubridge, E. A. (2009a). Human SCO2 Is Required for the Synthesis of CO II and as a Thiol-Disulphide Oxidoreductase for SCO1. Hum. Mol. Genet. 18, 2230-2240. doi:10.1093/ hmg/ddp158

Leary, S. C., Winge, D. R., and Cobine, P. A. (2009b). "Pulling the Plug" on Cellular Copper: The Role of Mitochondria in Copper export. Biochim. Biophys. ActaMolecular Cel Res. 1793, 146-153. doi:10.1016/j.bbamcr.2008.05.002

Li, Y. (2020). Copper Homeostasis: Emerging Target for Cancer Treatment. Iubmb Life 72, 1900-1908. doi:10.1002/iub.2341

Liebes, R., and Medeiros, D. M. (1997). Decreased Nuclear Encoded Subunits of Cytochrome C Oxidase and Increased Copper, Zinc-Superoxide Dismutase Activity Are Found in Cardiomyopathic Human Hearts. Int. J. Cardiol. 62, 259-267. doi:10.1016/s0167-5273(97)00254-4

Lill, R., and Freibert, S-A. (2020). Mechanisms of Mitochondrial Iron-Sulfur Protein Biogenesis. Annu. Rev. Biochem. 89, 471-499. doi:10.1146/annurevbiochem-013118-111540

Linder, M. C. (1991). Biochemistry of Copper. Springer US, 525

Linder, M. C., and Roboz, M. (1986). Turnover and Excretion of Copper in Rats as Measured with 67Cu. Am. J. Physiol. - Endocrinol. Metab. 251, E551-E55. doi:10.1152/ajpendo.1986.251.5.e551

Lipsky, P. E. (1984). Immunosuppression by D-Penicillamine In Vitro. Inhibition of Human $\mathrm{T}$ Lymphocyte Proliferation by Copper- or Ceruloplasmindependent Generation of Hydrogen Peroxide and protection by Monocytes. J. Clin. Invest. 73, 53-65. doi:10.1172/jci111207

Lipsky, P. E., and Ziff, M. (1980). Inhibition of Human Helper T Cell Function In Vitro by D-Penicillamine and $\mathrm{CuSO}(4)$. J. Clin. Invest. 65, 1069-1076. doi:10.1172/jci109759

Liu, H., Zhang, Y., Zheng, S., Weng, Z., Ma, J., Li, Y., et al. (2016). Detention of Copper by Sulfur Nanoparticles Inhibits the Proliferation of A375 Malignant Melanoma and MCF-7 Breast Cancer Cells. Biochem. Biophysical Res. Commun. 477, 1031-1037. doi:10.1016/j.bbrc.2016.07.026

Loh, S. N. (2010). The Missing Zinc: P53 Misfolding and Cancer. Metallomics 2, 442-449. doi:10.1039/c003915b

Lowndes, S. A., and Harris, A. L. (2004). Copper Chelation as an Antiangiogenic Therapy. Oncol. Res. Featuring Preclinical Clin. Cancer Ther. 14, 529-540. doi:10.3727/0965040042707952

Lowndes, S. A., and Harris, A. L. (2005). The Role of Copper in Tumour Angiogenesis. J. Mammary Gland Biol. Neoplasia 10, 299-310. doi:10.1007/ s10911-006-9003-7

Luchsinger, L. L., de Almeida, M. J., Corrigan, D. J., Mumau, M., and Snoeck, H-W. (2016). Mitofusin 2 Maintains Hematopoietic Stem Cells with Extensive Lymphoid Potential. Nature 529, 528-531. doi:10.1038/nature16500

Maryanovich, M., and Gross, A. (2013). A ROS Rheostat for Cell Fate Regulation. Trends Cell Biology 23, 129-134. doi:10.1016/j.tcb.2012.09.007

Matsubara, T., and Hirohata, K. (1988). Suppression of Human Fibroblast Proliferation by D-Penicillamine and Copper Sulfate In Vitro. Arthritis Rheum. 31, 964-972. doi:10.1002/art.1780310804 
McCord, J. M., and Fridovich, I. (1969). Superoxide Dismutase: AN ENZYMIC FUNCTION for ERYTHROCUPREIN (HEMOCUPREIN). J. Biol. Chem. 244, 6049-6055. doi:10.1016/s0021-9258(18)63504-5

Medeiros, D. M., and Jennings, D. (2002). Role of Copper in Mitochondrial Biogenesis via Interaction with ATP Synthase and Cytochrome C Oxidase. J. Bioenerg. Biomembr 34, 389-395. doi:10.1023/a:1021206220851

Medeiros, D. M., Shiry, L., and Samelman, T. (1997). Cardiac Nuclear Encoded Cytochrome C Oxidase Subunits Are Decreased with Copper Restriction but Not Iron Restriction: Gene Expression, Protein Synthesis and Heat Shock Protein Aspects. Comp. Biochem. Physiol. A. Physiol. 117, 77-87. doi:10.1016/ s0300-9629(96)00365-9

Mondola, P., Damiano, S., Sasso, A., and Santillo, M. (2016). The Cu, Zn Superoxide Dismutase: Not Only a Dismutase Enzyme. Front. Physiol. 7, 594. doi:10.3389/fphys.2016.00594

Morgada, M. N., Abriata, L. A., Cefaro, C., Gajda, K., Banci, L., and Vila, A. J. (2015). Loop Recognition and Copper-Mediated Disulfide Reduction Underpin Metal Site Assembly of $\mathrm{Cu}(\mathrm{A})$ in Human Cytochrome Oxidase. Proc. Natl. Acad. Sci. United States America 112, 11771-11776. doi:10.1073/ pnas. 1505056112

Narayanan, G., Bharathidevi, S. R., Vuyyuru, H., Muthuvel, B., and Konerirajapuram Natrajan, S. (2013). CTR1 Silencing Inhibits Angiogenesis by Limiting Copper Entry into Endothelial Cells. Plos One 8, e71982. doi:10.1371/journal.pone.0071982

Oe, S., Miyagawa, K., Honma, Y., and Harada, M. (2016). Copper Induces Hepatocyte Injury Due to the Endoplasmic Reticulum Stress in Cultured Cells and Patients with Wilson Disease. Exp. Cel Res. 347, 192-200. doi:10.1016/j.yexcr.2016.08.003

Oliveri, V., Lanza, V., Milardi, D., Viale, M., Maric, I., Sgarlata, C., et al. (2017). Amino- and Chloro-8-Hydroxyquinolines and Their Copper Complexes as Proteasome Inhibitors and Antiproliferative Agents. Metallomics 9, 1439-1446. doi:10.1039/c7mt00156h

Owen, C. A. J. (1971). Metabolism of Copper 67 by the Copper-Deficient Rat. Am. J. Physiology-Legacy Content 221, 1722-1727. doi:10.1152/ ajplegacy.1971.221.6.1722

Pacheu-Grau, D., Wasilewski, M., Oeljeklaus, S., Gibhardt, C. S., Aich, A., Chudenkova, M., et al. (2020). COA6 Facilitates Cytochrome C Oxidase Biogenesis as Thiol-Reductase for Copper Metallochaperones in Mitochondria. J. Mol. Biol. 432, 2067-2079. doi:10.1016/j.jmb.2020.01.036

Pan, Q., Kleer, C. G., van Golen, K. L., Irani, J., Bottema, K. M., Bias, C., et al. (2002). Copper Deficiency Induced by Tetrathiomolybdate Suppresses Tumor Growth and Angiogenesis. Cancer Res. 62, 4854-4859.

Parke, A., Bhattacherjee, P., Palmer, R. M., and Lazarus, N. R. (1988). Characterization and Quantification of Copper Sulfate-Induced Vascularization of the Rabbit Cornea. Am. J. Pathol. 130, 173-178.

Pass, H. I., Brewer, G. J., Dick, R., Carbone, M., and Merajver, S. (2008). A Phase II Trial of Tetrathiomolybdate after Surgery for Malignant Mesothelioma: Final Results. Ann. Thorac. Surg. 86, 383-390. doi:10.1016/j.athoracsur.2008.03.016

Peled, T., Glukhman, E., Hasson, N., Adi, S., Assor, H., Yudin, D. K., et al. (2005). Chelatable Cellular Copper Modulates Differentiation and Self-Renewal of Cord Blood-Derived Hematopoietic Progenitor Cells. Exp. Hematol. 33, 1092-1100. doi:10.1016/j.exphem.2005.06.015

Peled, T., Landau, E., Prus, E., Treves, A. J., and Fibach, E. (2002). Cellular Copper Content Modulates Differentiation and Self-renewal in Cultures of Cord Bloodderived CD34+ Cells. Br. J. Haematol. 116, 655-661. doi:10.1046/j.00071048.2001.03316.x

Pettenuzzo, N., Brustolin, L., Coltri, E., Gambalunga, A., Chiara, F., Trevisan, A., et al. (2019). CuII and AuIII Complexes with Glycoconjugated Dithiocarbamato Ligands for Potential Applications in Targeted Chemotherapy. ChemMedChem 14, 1162-1172. doi:10.1002/cmdc.201900226

Piccoli, C., Agriesti, F., Scrima, R., Falzetti, F., Di Ianni, M., and Capitanio, N. (2013). To Breathe or Not to Breathe: the Haematopoietic Stem/progenitor Cells Dilemma. Br. J. Pharmacol. 169, 1652-1671. doi:10.1111/bph.12253

Piccoli, C., Ria, R., Scrima, R., Cela, O., D'Aprile, A., Boffoli, D., et al. (2005). Characterization of Mitochondrial and Extra-mitochondrial Oxygen Consuming Reactions in Human Hematopoietic Stem Cells: NOVEL EVIDENCE of the OCCURRENCE of NAD(P)H OXIDASE ACTIVITY *. J. Biol. Chem. 280, 26467-26476. doi:10.1074/jbc.m500047200
Piccoli, C., Scrima, R., Boffoli, D., and Capitanio, N. (2006). Control by Cytochrome C Oxidase of the Cellular Oxidative Phosphorylation System Depends on the Mitochondrial Energy State. Biochem. J. 396, 573-583. doi:10.1042/bj20060077

Porcu, C., Antonucci, L., Barbaro, B., Illi, B., Nasi, S., Martini, M., et al. (2018). Copper/MYC/CTR1 Interplay: a Dangerous Relationship in Hepatocellular Carcinoma. Oncotarget 9, 9325-9343. doi:10.18632/ oncotarget. 24282

Puig, S., and Thiele, D. J. (2002). Molecular Mechanisms of Copper Uptake and Distribution. Curr. Opin. Chem. Biol. 6, 171-180. doi:10.1016/s1367-5931(02) 00298-3

Qin, Z., Gongora, M. C., Ozumi, K., Itoh, S., Akram, K., Ushio-Fukai, M., et al. (2008). Role of Menkes ATPase in Angiotensin II-Induced Hypertension. A Key Modulator Extracellular Superoxide Dismutase Funct. 52, 945-951. doi:10.1161/ hypertensionaha.108.116467

Qiu, L., Ding, X., Zhang, Z., and Kang, Y. J. (2012). Copper Is Required for CobaltInduced Transcriptional Activity of Hypoxia-Inducible Factor-1. J. Pharmacol. Exp. Ther. 342, 561-567. doi:10.1124/jpet.112.194662

Redman, B. G., Esper, P., Pan, Q., Dunn, R. L., Hussain, H. K., Chenevert, T., et al. (2003). Phase II Trial of Tetrathiomolybdate in Patients with Advanced Kidney Cancer. Clin. Cancer Res. 9, 1666-1672.

Rhee, S. G., Yang, K-S., Kang, S. W., Woo, H. A., and Chang, T-S. (2005). Controlled Elimination of Intracellular H2O2: Regulation of Peroxiredoxin, Catalase, and Glutathione Peroxidase via Post-translational Modification. Antioxid. Redox Signaling 7, 619-626. doi:10.1089/ars.2005.7.619

Robinson, N. J., and Winge, D. R. (2010). Copper Metallochaperones. Annu. Rev. Biochem. 79, 537-562. doi:10.1146/annurev-biochem-030409-143539

Rodríguez, J., Ríos, S., and González, M. (2002). Modulation of the Proliferation and Differentiation of Human Mesenchymal Stem Cells by Copper. J. Cel Biochem 85, 92-100. doi:10.1002/jcb.10111

Rossi, L., Lippe, G., Marchese, E., De Martino, A., Mavelli, I., Rotilio, G., et al. (1998). Decrease of Cytochrome C Oxidase Protein in Heart Mitochondria of Copper-Deficient Rats. Biometals 11, 207-212. doi:10.1023/a: 1009274131473

Rossi, L., Lombardo, M. F., Ciriolo, M. R., and Rotilio, G. (2004). Mitochondrial Dysfunction in Neurodegenerative Diseases Associated with Copper Imbalance. Neurochem. Res. 29, 493-504. doi:10.1023/b: nere.0000014820.99232.8a

Ruiz, L. M., Jensen, E. L., Bustos, R. I., Argüelloa, G., Gutierrez-Garcia, R., González, M., et al. (2014). Adaptive Responses of Mitochondria to Mild Copper Deprivation Involve Changes in Morphology, OXPHOS Remodeling and Bioenergetics. J. Cell Physiol. 229, 607-619. doi:10.1002/jcp.24484

Ruiz, L. M., Jensen, E. L., Rossel, Y., Puas, G. I., Gonzalez-Ibanez, A. M., Bustos, R. I., et al. (2016). Non-cytotoxic Copper Overload Boosts Mitochondrial Energy Metabolism to Modulate Cell Proliferation and Differentiation in the Human Erythroleukemic Cell Line K562. Mitochondrion 29, 18-30. doi:10.1016/ j.mito.2016.04.005

Ruiz-Azuara, L., and Bravo-Gomez, M. E. (2010). Copper Compounds in Cancer Chemotherapy. Curr. Med. Chem. 17, 3606-3615. doi:10.2174/ 092986710793213751

Scanni, A., Licciardello, L., Trovato, M., Tomirotti, M., and Biraghi, M. (1977). Serum Copper and Ceruloplasmin Levels in Patients with Neoplasias Localized in the Stomach, Large Intestine or Lung. Tumori 63, 175-180. doi:10.1177/ 030089167706300208

Schagger, H., and Pfeiffer, K. (2000). Supercomplexes in the Respiratory Chains of Yeast and Mammalian Mitochondria. EMBO J. 19, 1777-1783. doi:10.1093/ emboj/19.8.1777

Schulze, A., and Harris, A. L. (2012). How Cancer Metabolism Is Tuned for Proliferation and Vulnerable to Disruption. Nature 491, 364. doi:10.1038/ nature 11706

Shoubridge, E. A. (2012). Supersizing the Mitochondrial Respiratory Chain. Cel Metab. 15, 271-272. doi:10.1016/j.cmet.2012.02.009

Soma, S., Morgada, M. N., Naik, M. T., Boulet, A., Roesler, A. A., Dziuba, N., et al. (2019). COA6 Is Structurally Tuned to Function as a Thiol-Disulfide Oxidoreductase in Copper Delivery to Mitochondrial Cytochrome C Oxidase. Cel Rep. 29, 4114-4126. doi:10.1016/j.celrep.2019.11.054 
Soncin, F., Guitton, J-D., Cartwright, T., and Badet, J. (1997). Interaction of Human Angiogenin with Copper Modulates Angiogenin Binding to Endothelial Cells. Biochem. Biophysical Res. Commun. 236, 604-610. doi:10.1006/bbrc.1997.7018

Stroud, D. A., Maher, M. J., Lindau, C., Vögtle, F-N., Frazier, A. E., Surgenor, E., et al. (2015). COA6 Is a Mitochondrial Complex IV Assembly Factor Critical for Biogenesis of mtDNA-Encoded COX2. Hum. Mol. Genet. 24, 5404-5415. doi: $10.1093 / \mathrm{hmg} / \mathrm{ddv} 265$

Su, R., Wang, R., Guo, S., Cao, H., Pan, J., Li, C., et al. (2011). In Vitro effect of Copper Chloride Exposure on Reactive Oxygen Species Generation and Respiratory Chain Complex Activities of Mitochondria Isolated from Broiler Liver. Biol. Trace Elem. Res. 144, 668-677. doi:10.1007/s12011-011-9039-4

Suska, F., Esposito, M., Gretzer, C., Källtorp, M., Tengvall, P., and Thomsen, P. (2003). IL-1 $\alpha$, IL-1 $\beta$ and TNF- $\alpha$ Secretion during In Vivo/Ex Vivo Cellular Interactions with Titanium and Copper. Biomaterials 24, 461-468. doi:10.1016/ s0142-9612(02)00359-9

Takubo, K., Goda, N., Yamada, W., Iriuchishima, H., Ikeda, E., Kubota, Y., et al. (2010). Regulation of the HIF-1 Alpha; Level Is Essential for Hematopoietic Stem Cells. Cell Stem Cell 7, 391-402. doi:10.1016/j.stem.2010.06.020

Teknos, T. N., Islam, M., Arenberg, D. A., Pan, Q., Carskadon, S. L., Abarbanell, A. M., et al. (2005). The Effect of Tetrathiomolybdate on Cytokine Expression, Angiogenesis, and Tumor Growth in Squamous Cell Carcinoma of the Head and Neck. Arch. Otolaryngology-Head Neck Surg. 131, 204-211. doi:10.1001/archotol.131.3.204

Tisato, F., Marzano, C., Porchia, M., Pellei, M., and Santini, C. (2010). Copper in Diseases and Treatments, and Copper-Based Anticancer Strategies. Med. Res. Rev. 30, 708-749. doi:10.1002/med.20174

Tsang, T., Posimo, J. M., Gudiel, A. A., Cicchini, M., Feldser, D. M., and Brady, D. C. (2020). Copper Is an Essential Regulator of the Autophagic Kinases ULK1/2 to Drive Lung Adenocarcinoma. Nat. Cel Biol. 22, 412-424. doi:10.1038/s41556-020-0481-4

Turnlund, J. R., Keyes, W. R., Peiffer, G. L., and Scott, K. C. (1998). Copper Absorption, Excretion, and Retention by Young Men Consuming Low Dietary Copper Determined by Using the Stable Isotope 65Cu. Am. J. Clin. Nutr. 67, 1219-1225. doi:10.1093/ajcn/67.6.1219

Turski, M. L., and Thiele, D. J. (2009). New Roles for Copper Metabolism in Cell Proliferation, Signaling, and Disease. J. Biol. Chem. 284, 717-721. doi:10.1074/ jbc.r800055200

Ungar-Waron, H., Gluckman, A., Spira, E., Waron, M., and Trainin, Ze. (1978). Ceruloplasmin as a Marker of Neoplastic Activity in Rabbits Bearing the VX-2 Carcinoma. Cancer Res. 38, 1296-1299.

Vallières, C., Holland, S. L., and Avery, S. V. (2017). Mitochondrial Ferredoxin Determines Vulnerability of Cells to Copper Excess. Cel Chem. Biol. 24, 1228-1237. doi:10.1016/j.chembiol.2017.08.005

Vest, K. E., Leary, S. C., Winge, D. R., and Cobine, P. A. (2013). Copper Import into the Mitochondrial Matrix in Saccharomyces cerevisiae Is Mediated by Pic2, a Mitochondrial Carrier Family Protein. J. Biol. Chem. 288, 23884-23892. doi:10.1074/jbc.m113.470674

Vest, K. E., Wang, J., Gammon, M. G., Maynard, M. K., White, O. L., Cobine, J. A., et al. (2016). Overlap of Copper and Iron Uptake Systems in Mitochondria in Saccharomyces cerevisiae. Open Biol. 6, 150223. doi:10.1098/rsob.150223

Voli, F., Valli, E., Lerra, L., Kimpton, K., Saletta, F., Giorgi, F., et al. (2020). Intratumoral Copper Modulates PD-L1 Expression and Influences Tumor Immune Evasion. Cancer Res. 80, 4129-4144. doi:10.1158/0008-5472.can-20-0471

Vozza, A., Parisi, G., De Leonardis, F., Lasorsa, F. M., Castegna, A., Amorese, D., et al. (2014). UCP2 Transports C4 Metabolites Out of Mitochondria, Regulating Glucose and Glutamine Oxidation. Proc. Natl. Acad. Sci. United States America 111, 960-965. doi:10.1073/pnas.1317400111

Wagner, K. U., Claudio, E., Rucker, E. B., Riedlinger, G., Broussard, C., Schwartzberg, P. L., et al. (2000). Conditional Deletion of the Bcl-X Gene from Erythroid Cells Results in Hemolytic Anemia and Profound Splenomegaly. Development 127, 4949-4958. doi:10.1242/dev.127.22.4949

Wakabayashi, T., Asano, M., and Kurono, C. (1975). Mechanism of the Formation of Mega Mitochondria Induced by Copper Chelating Agents Part 1 on the Formation Process of Mega Mitochondria in Cuprizone Treated Mouse Liver. Acta Pathol. Jpn. 25, 15-38. doi:10.1111/j.1440-1827.1975.tb00147.x

Wakabayashi, T. (2002). Megamitochondria Formation - Physiology and Pathology. J. Cel Mol Med 6, 497-537. doi:10.1111/j.1582-4934.2002.tb00452.x

Wanet, A., Arnould, T., Najimi, M., and Renard, P. (2015). Connecting Mitochondria, Metabolism, and Stem Cell Fate. Stem Cell Dev. 24, 1957-1971. doi:10.1089/scd.2015.0117
Wang, J., Chen, J., Tang, Z., Li, Y., Hu, L., and Pan, J. (2016). The Effects of Copper on Brain Microvascular Endothelial Cells and Claudin via Apoptosis and Oxidative Stress. Biol. Trace Elem. Res. 174, 132-141. doi:10.1007/s12011016-0685-4

Wang, J., Luo, C., Shan, C., You, Q., Lu, J., Elf, S., et al. (2015). Inhibition of Human Copper Trafficking by a Small Molecule Significantly Attenuates Cancer Cell Proliferation. Nat. Chem. 7, 968-979. doi:10.1038/nchem.2381

Wang, Y., Branicky, R., Noë, A., and Hekimi, S. (2018). Superoxide Dismutases: Dual Roles in Controlling ROS Damage and Regulating ROS Signaling. J. Cel. Biol. 217, 1915-1928. doi:10.1083/jcb.201708007

Xu, W., Barrientos, T., and Andrews Nancy, C. (2013a). Iron and Copper in Mitochondrial Diseases. Cel Metab. 17, 319-328. doi:10.1016/j.cmet.2013.02.004

Xu, X., Duan, S., Yi, F., Ocampo, A., Liu, G-H., and Izpisua Belmonte Juan, C. (2013b). Mitochondrial Regulation in Pluripotent Stem Cells. Cel Metab. 18, 325-332. doi:10.1016/j.cmet.2013.06.005

Yonashiro, R., Sugiura, A., Miyachi, M., Fukuda, T., Matsushita, N., Inatome, R., et al. (2009). Mitochondrial Ubiquitin Ligase MITOL Ubiquitinates Mutant SOD1 and Attenuates Mutant SOD1-Induced Reactive Oxygen Species Generation. Mol. Biol. Cel 20, 4524-4530. doi:10.1091/mbc.e09-02-0112

Yoon, Y., Krueger, E. W., Oswald, B. J., and McNiven, M. A. (2003). The Mitochondrial Protein hFis1 Regulates Mitochondrial Fission in Mammalian Cells through an Interaction with the Dynamin-like Protein DLP1. Mol. Cell Biol. 23, 5409-5420. doi:10.1128/mcb.23.15.5409-5420.2003

Yoshida, D., Ikeda, Y., and Nakazawa, S. (1995). Suppression Of Tumor Growth In Experimental $9 L$ Gliosarcoma Model By Copper Depletion. Neurologia medicochirurgica 35, 133-135. doi:10.2176/nmc.35.133

Yoshii, J., Yoshiji, H., Kuriyama, S., Ikenaka, Y., Noguchi, R., Okuda, H., et al. (2001). The Copper-Chelating Agent, Trientine, Suppresses Tumor Development and Angiogenesis in the Murine Hepatocellular Carcinoma Cells. Int. J. Cancer 94, 768-773. doi:10.1002/ijc.1537

Zelko, I. N., Mariani, T. J., and Folz, R. J. (2002). Superoxide Dismutase Multigene Family: a Comparison of the CuZn-SOD (SOD1), Mn-SOD (SOD2), and ECSOD (SOD3) Gene Structures, Evolution, and Expression. Free Radic. Biol. Med. 33, 337-349. doi:10.1016/s0891-5849(02)00905-x

Zeng, H., Saari, J. T., and Johnson, W. T. (2007). Copper Deficiency Decreases Complex IV but Not Complex I, II, III, or V in the Mitochondrial Respiratory Chain in Rat Heart. J. Nutr. 137, 14-18. doi:10.1093/jn/137.1.14

Zhang, J., Khvorostov, I., Hong, J., Oktay, Y., Vergnes, L., Nuebel, E., et al. (2011). UCP2 Regulates Energy Metabolism and Differentiation Potential of Human Pluripotent Stem Cells. EMBO J. 30, 4860-4873. doi:10.1038/emboj.2011.401

Zhang, W., Chen, C., Shi, H., Yang, M., Liu, Y., Ji, P., et al. (2016). Curcumin Is a Biologically Active Copper Chelator with Antitumor Activity. Phytomedicine 23, 1-8. doi:10.1016/j.phymed.2015.11.005

Zidar, B. L., Shadduck, R. K., Zeigler, Z., and Winkelstein, A. (1977). Observations on the Anemia and Neutropenia of Human Copper Deficiency. Am. J. Hematol. 3, 177-185. doi:10.1002/ajh.2830030209

Zuo, J., Bi, C., Fan, Y., Buac, D., Nardon, C., Daniel, K. G., et al. (2013). Cellular and Computational Studies of Proteasome Inhibition and Apoptosis Induction in Human Cancer Cells by Amino Acid Schiff Base-Copper Complexes. J. Inorg. Biochem. 118, 83-93. doi:10.1016/j.jinorgbio.2012.10.006

Conflict of Interest: The authors declare that the research was conducted in the absence of any commercial or financial relationships that could be construed as a potential conflict of interest.

Publisher's Note: All claims expressed in this article are solely those of the authors and do not necessarily represent those of their affiliated organizations, or those of the publisher, the editors and the reviewers. Any product that may be evaluated in this article, or claim that may be made by its manufacturer, is not guaranteed or endorsed by the publisher.

Copyright (c) 2021 Ruiz, Libedinsky and Elorza. This is an open-access article distributed under the terms of the Creative Commons Attribution License (CC $B Y)$. The use, distribution or reproduction in other forums is permitted, provided the original author(s) and the copyright owner(s) are credited and that the original publication in this journal is cited, in accordance with accepted academic practice. No use, distribution or reproduction is permitted which does not comply with these terms. 